Research Paper

\title{
A constitutive model for granular materials subjected to a large stress range
}

\author{
Lin Liu ${ }^{\mathrm{a}, \mathrm{b}}$, Yangping Yao ${ }^{\mathrm{a}, *}$, Ting Luo ${ }^{\mathrm{a}}$, Annan Zhou ${ }^{\mathrm{a}, \mathrm{c}}$ \\ ${ }^{a}$ School of Transportation Science and Engineering, Beihang University, Beijing 100191, China \\ ${ }^{\mathrm{b}}$ Institute of Mechanics, Chinese Academy of Sciences, Beijing 100190, China \\ ${ }^{\mathrm{c}}$ School of Civil, Environmental and Chemical Engineering, Royal Melbourne Institute of Technology (RMIT), Melbourne, Australia
}

\section{A R T I C L E I N F O}

\section{Keywords:}

Granular materials

Constitutive behavior

Large stress range

Particle crushing

High stress

Constitutive model

\begin{abstract}
A B S T R A C T
A simple constitutive model is presented to represent the behavior of granular materials subjected to a large stress range by introducing a revised normal compression line with a limit void ratio $\left(e_{\mathrm{L}}\right)$ in the double logarithmic scale and a state parameter $(\xi)$ to quantify the state of granular materials. In the proposed model, a dropshaped yield surface is employed and a unified hardening parameter $(H)$ that is a function of the state parameter $(\xi)$ is developed to govern the hardening process. The model is first established in the triaxial compression stress state and then is extended to the general stress state through the transformed stress (TS) method. Adopting a single set of material parameters, the proposed model is verified against the experimental results of various tests on Cambria sand at different confining pressures (0.25-68.9 MPa), including the data of isotropic compression test and drained/undrained triaxial compression/extension tests.
\end{abstract}

\section{Introduction}

Granular materials have been widely used in various aspects of geotechnical engineering, such as dam and pavement. The mechanical behaviors of the granular materials govern the engineering safety and deformation, and thus received considerable attention from scientific and engineering communities. Because most of the engineering problems are at low pressure level (see Table 1), the research on the mechanical properties of granular materials focuses on low pressures historically [1-7]. However, with the development of society and economy, a lot of practical geotechnical problems involve high or very high stresses. For example, natural gas hydrate has become a potential clean energy after oil and natural gas energy. Nevertheless, natural gas hydrates generally accumulate in the depth range of $200-1100 \mathrm{~m}$ in the terrestrial permafrost zone, or below $1200 \mathrm{~m}$ in the seawater zone and in the depth range of $300 \mathrm{~m}$ in the seabed [8]. These may result in well shafts experiencing high stress level of soil pressures. Additionally, soils under the tips of piles supporting the high-rise buildings or subjected to explosions may experience much higher stresses. Therefore, it is very important to research and describe the behavior of soils subjected to high stresses to assist in the solution to these geotechnical engineering problems.

It is known that particle crushing is the unique microphenomenon of granular materials, and can cause the special macroscopic mechanical properties of granular materials different from that of clays, especially at high stress. Many researchers have obtained some basic laws of these macroscopic mechanical properties through laboratory experiments. In the past sixty years, a number of one-dimensional compression tests at high stresses has been conducted on various granular materials. According to one-dimensional compression experiments on sand and ground quartz up to $140 \mathrm{MPa}$, Roberts and de Souza [10] observed that large deformation occur when vertical stress increases beyond a "critical pressure", which mainly caused by particle breakage, and found that the initial void ratio is the chief factor to control the "critical pressure". Hendron [11] carried out confined compression experiments on four different kinds of sands, and concluded that the initial density is the most important variable at low pressures, and its effect is reduced gradually with the vertical stress increasing. The compression lines of sands with different initial densities converge onto single loading paths of unique void ratios at high pressures. Hagerty et al. [12] carried out one-dimensional compression tests on Ottawa sand subjected up to $689 \mathrm{MPa}$, and found that the compression process of sand includes three phases: particle arrangement at low stresses, particle crushing and rearrangement under higher stresses and fractured particles at very high stresses. Yamamuro et al. [13] developed a one-dimensional testing apparatus with axial stresses up to $850 \mathrm{MPa}$. Using this apparatus, they carried out a series of onedimensional compression tests of three sands with different mineral hardness. They pointed out that the magnitude of stress at which these compression curves join each other and the minimum void ratio at the

\footnotetext{
* Corresponding author.

E-mail addresses: liulin@imech.ac.cn (L. Liu), ypyao@buaa.edu.cn (Y. Yao), tluo@buaa.edu.cn (T. Luo), annan.zhou@outlook.com (A. Zhou).
} 


\begin{tabular}{|c|c|c|c|}
\hline \multicolumn{2}{|c|}{ Nomenclature } & \multirow{3}{*}{$\begin{array}{l}q \\
\widetilde{q} \\
Z\end{array}$} & \multirow{3}{*}{$\begin{array}{l}\text { deviator stress } \\
\text { transformed deviator stress } \\
\text { location of normal compression line for sands in the } e-\ln p \\
\text { plane }\end{array}$} \\
\hline $\mathrm{D}_{i k l t}^{\mathrm{e}}$ & elastic constitutive tensor & & \\
\hline $\begin{array}{l}\mathrm{D}_{i j k l} \\
\mathrm{D}_{i j k l}^{\mathrm{ep}}\end{array}$ & elastoplastic constitutive tensor & & \\
\hline$e_{0}$ & initial void ratio & $\lambda$ & slop of normal compression line in the $\ln \left(e-e_{\mathrm{L}}\right)-\ln \left(p+p_{\mathrm{s}}\right)$ \\
\hline$e$ & void ratio & & plane, also is the slop of asymptotic line in the $e-\ln \left(p+p_{\mathrm{s}}\right)$ \\
\hline$e_{\eta}$ & $\begin{array}{l}\text { void ratio on the anisotropic compression line with its } \\
\text { stress ratio being } \eta\end{array}$ & $\kappa$ & $\begin{array}{l}\text { plane } \\
\text { slop of the unloading line in the } \ln \left(e-e_{\mathrm{L}}\right)-\ln \left(p+p_{\mathrm{s}}\right) \text { plane }\end{array}$ \\
\hline$e_{\mathrm{c} 0}$ & $\begin{array}{l}\text { void ratio on the critical state line at the mean effective } \\
\text { stress } p=0 \mathrm{kPa}\end{array}$ & $\eta$ & $\begin{array}{l}\text { stress ratio } \\
\text { transformed stress ratio }\end{array}$ \\
\hline E & elastic modulus & $v$ & Poisson's ratio \\
\hline$G$ & elastic shear modulus & $\chi$ & critical state parameter \\
\hline$H$ & unified hardening parameter & $\xi$ & state parameter describing the current density \\
\hline$K$ & elastic bulk modulus & $\xi_{c}$ & value of $\xi$ at the characteristic state point $\left(\eta=M_{\mathrm{c}}^{\xi_{\mathrm{c}}}\right)$ \\
\hline$L$ & Lame's constant & $\begin{array}{l}{ }_{c}^{c} \\
\varepsilon_{\mathrm{V}}\end{array}$ & volumetric strain \\
\hline$m$ & dilatancy parameter & $\varepsilon_{\mathrm{v}}^{\mathrm{e}}$ & elastic volumetric strain \\
\hline$M$ & critical state stress ratio & $\varepsilon_{\mathrm{v}}^{\mathrm{p}}$ & plastic volumetric strain \\
\hline$M_{\mathrm{f}}$ & potential failure stress ratio & $\varepsilon_{\mathrm{d}}^{\mathrm{p}}$ & plastic deviator strain \\
\hline$M_{\mathrm{c}}$ & characteristic state stress ratio & $\varepsilon_{i j}^{\mathrm{e}}$ & elastic strain \\
\hline$M_{\mathrm{c}}^{\xi_{\mathrm{c}}}$ & characteristic state stress ratio according to $\xi_{c}$ & $\varepsilon_{i j}^{\mathrm{p}}$ & plastic strain \\
\hline$N$ & location of asymptotic line in the $e-\ln p$ plane & $\delta_{i j}$ & Kronecker's delta \\
\hline$p$ & mean effective stress & $\sigma_{i j}$ & stress tensor \\
\hline$\widetilde{p}$ & transformed mean effective stress & $\tilde{\sigma}_{i j}$ & TS tensor \\
\hline$p_{x 0}$ & $\begin{array}{l}\text { intersection of the current yield surface with the } p \text {-axis in } \\
\text { the initial condition }\end{array}$ & $\tilde{\Lambda}$ & $\begin{array}{l}\text { plastic factor } \\
\text { plastic factor in TS space }\end{array}$ \\
\hline $\begin{array}{l}p_{x} \\
p_{y} \\
p_{\mathrm{s}}\end{array}$ & $\begin{array}{l}\text { intersection of the current yield surface with the } p \text {-axis } \\
\text { intersection of the plastic potential surface with the } p \text {-axis } \\
\text { compressive hardening parameter according to } Z\end{array}$ & $\Delta e_{p}$ & $\begin{array}{l}\text { vertical distance between normal compression line and } \\
\text { critical state line in the } e \text { - } p \text { or } e \text {-lnp plane at the mean stress } \\
\text { effective } p\end{array}$ \\
\hline
\end{tabular}

Table 1

Distribution of stress [9].

\begin{tabular}{|c|c|c|c|c|c|c|}
\hline & Very low & Low & Medium high & High & Very high & Ultra-high \\
\hline Stress range & $0.1-10 \mathrm{kPa}$ & $10 \mathrm{kPa}-1 \mathrm{MPa}$ & $1-10 \mathrm{MPa}$ & $10-100 \mathrm{MPa}$ & $100-1000 \mathrm{MPa}$ & $1000 \mathrm{MPa}-$ \\
\hline $\begin{array}{l}\text { Geotechnical } \\
\text { conditions }\end{array}$ & $\begin{array}{l}\text { Deep-sea surface } \\
\text { sediment }\end{array}$ & $\begin{array}{l}\text { Common geotechnical } \\
\text { engineering }\end{array}$ & $\begin{array}{l}\text { High rockfill } \\
\text { dam }\end{array}$ & $\begin{array}{l}\text { Natural gas hydrate bearing } \\
\text { soil; deep mine shafts }\end{array}$ & $\begin{array}{l}\text { Soils under the tips of driven pile, } \\
\text { Soils subjected to explosions }\end{array}$ & \\
\hline
\end{tabular}

maximum stress appear to be related to the mineral hardness. The softer the mineral hardness, the lower the minimum void ratio at the maximum stress.

However, only a few studies examining behaviors of granular materials have been published at high confining pressures (above a confining pressure of $10 \mathrm{MPa}$ ). Yamamuro and Lade [14] performed a series of drained triaxial compression and extension tests on dense Cambria sand at various confining pressures between 0.25 and $52 \mathrm{MPa}$. They observed the overall stress-strain and volume change behavior, and concluded the following mechanical properties for granular materials. (a) At low confining pressures, particle crushing is not significant throughout the test. With increasing confining pressure, particle crushing occurs, and the volumetric changes gradually from dilatancy to contraction in drained triaxial compression and extension tests. (b) At higher confining pressures, the lower void ratios are obtained in the isotropic consolidation, which allows less volumetric contraction. Therefore, the volumetric strain reaches the maximum value at a higher confining pressures, and then decreases as the confining pressures continue to increase. (c) The location of the critical state line (CSL) in the $e-\log p$ space is affected by particle crushing. At low confining pressure, the CSL obtained by compression test is located above that obtained by extension test. At higher mean normal stresses, the CSL obtained by extension test is located above that obtained by compression test. Furthermore, Lade and Yamamuro [15] performed undrained triaxial compression and extension tests on dense Cambria sand between initial effective confining pressures of 6.4 MPa and 68.9 MPa. These undrained tests suggest the following mechanical properties for granular materials. (a) The maximum principal stress differences occur at very low major principal strain values, and well inside the effective stress failure envelope in the $p-q$ space. This indicates that granular materials do not behave in accordance with associated plastic flow rules as the modified Cam-clay model. (b) The slopes of effective failure envelopes in the $p-q$ space are different under compression and extension conditions. The slope under compression condition is larger than that under extension condition. (c) At high confining pressures, the peak strength lines from drained and undrained compression and extension tests merges into one unique line, rather than the failure strength lines (i.e. CSL).

Overall, the behaviors of granular materials are quite complex at the high confining pressures. It is very challenging for researchers to describe these properties well by developing a simple constitutive model with limited number of material parameters. Yu [16] introduced a state parameter into the Cam-clay model and developed a unified model called CASM. Daouadji et al. [17] proposed an elastoplastic constitutive model for granular soils considering particle crushing. Based on the concepts of critical state soil mechanics, Yao et al. [18] developed a unified hardening model for clays and sands referred to as the CSUH model. However, a common weakness of the models mentioned above is that the pore volume will be negative at high stress, so they are incapable of describing the behaviors of granular materials at high stresses. Pestana and Whittle [9] assumed a linear relation between the logarithmic void ratio and the logarithmic mean stress and developed a compression model. Wan and Guo [19] proposed a constitutive model for granular soils by modifying the original Rowe's equation (referred 
to as a modified stress-dilatancy law). Li and Dafalias [20] presented a rudimentary model treating the dilatancy as a state-dependent quantity. Based on the concepts of critical state soil mechanics, Russell and Khalili [21] provided a function to describe the uniquely shaped critical state line across a wide range of stresses, and proposed a bounding surface plasticity model for sands. Although these models avoid negative pore volume at high stress, it has not been verified that they can reasonably describe the mechanic behaviors of granular materials at high stress. Fig. 1 shows the maximum and minimum confining pressures of tests used to verify the models in the literatures mentioned above and the ratio of maximum confining pressure to minimum confining pressure. Noting that the larger the ratio, the larger the range of confining pressure. It can be seen that the maximum confining pressure is $15 \mathrm{MPa}$ and the maximum ratio is 156 .

This paper focuses on the development of a simple and practical constitutive model for granular materials which is valid in a broad stress range. This paper is organized as follows. By introducing a limit void ratio, a simple equation is proposed to define the NCL in the double logarithmic coordinates. The state parameter considering the effects of shear stress is employed to quantify the states of granular materials and a unified hardening parameter is proposed to govern the hardening process. The elastoplastic constitutive model for triaxial compression stress states is proposed and then extended to be a threedimensional constitutive model through the transformed stress (TS) method [22]. Finally, the model is validated by the results [13-15] from (a) Isotropic compression test $\left(\sigma_{3}=0.25-80 \mathrm{MPa}\right)$ and one-dimensional compression tests $\left(\sigma_{3}=0.1-850 \mathrm{MPa}\right)$, (b) Drained triaxial compression tests $\left(\sigma_{3}=2.1-52 \mathrm{MPa}\right)$, (c) Drained triaxial extension tests $\left(\sigma_{3}=0.25-52 \mathrm{MPa}\right)$, (d) Undrained triaxial compression tests $\left(\sigma_{3}=6.4-68.9 \mathrm{MPa}\right)$, and (e) Undrained triaxial extension tests $\left(\sigma_{3}=12-52 \mathrm{MPa}\right)$.

\section{Constitutive model for granular materials}

\subsection{Normal compression line}

\subsubsection{Behaviors of granular materials under compression condition}

Several representative one-dimensional compression lines of Quiou sand [12] with different initial void ratios are presented in Fig. 2. As shown in Fig. 2, dots represent the test results and dashed lines represent the best fits of the results. It is observed that the shapes of all compression lines are similar to each other and feature an S-shape in general in the $e$-ln $p$ space. The S-shape compression lines have been

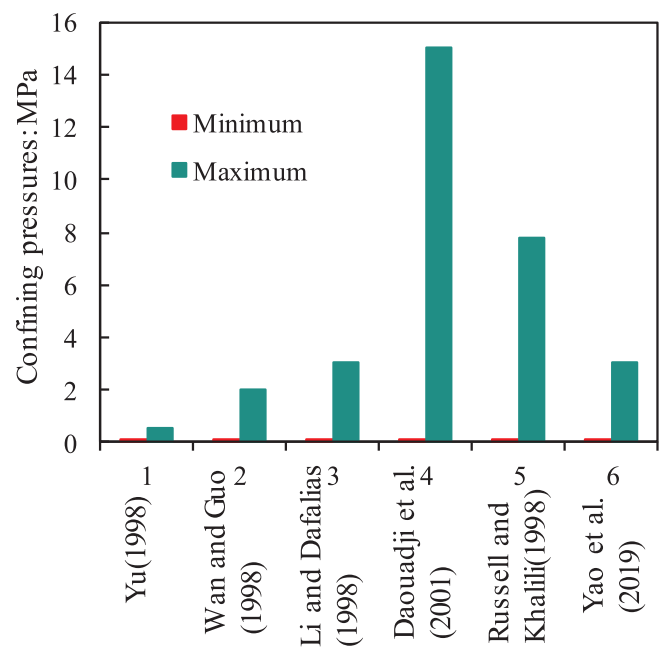

interpreted by different physical mechanisms for the entire compression process [23-26]. In general, the compression process of granular material includes the following four stages.

In the first stage (i.e., low stress level), the stress is less than the yield stress (namely the stress at the maximum curvature of compression line in the $e$-ln $p$ space), thus only limited particle crushing occurs, caused by surface abrasion and attrition breaking. In the first stage, the deformation is mainly attributed to rearrangement of particle including sliding and rotation, and the compression line in the $e-\ln p$ space is flat (see the segment between Point A and Point B in Fig. 2).

In the second stage (i.e., medium stress level), the stress is larger than the yield stress (Point B), and particle crushing starts to become distinct. New crushed particles are generated and fill the voids, and the deformation mechanism gradually changes from particle rearrangement to particle crushing. When the stress keep increasing, particle crushing becomes the main deformation mechanism and silt particles (fines) begin to appear. The slope of the compression line gradually increases along with the increase of stress (see the segment between Point B and Point C in Fig. 2).

In the third stage (i.e., high stress level), the larger particles are surrounded by many smaller particles and the well-graded distribution is formed. In this stage, particle crushing is no longer the main deformation mechanism and the slope of the compression line decreases along with the increase of the stress (see the segment between Point $C$ and Point $D$ in Fig. 2).

As the stress remains increasing, the change in the volume gradually decreases. According to the test results [13], the void ratio does not necessarily decrease to 0 when the stress is less than $1000 \mathrm{MPa}$ (involving the corresponding geotechnical engineering conditions), and will reach a minimum/limit (see Point D in Fig. 2). Surprisingly, the minimum/limit void ratios are different for different granular materials, and appear to be related to the value of mineral hardness [13].

\subsubsection{New normal compression line}

The normal compression line (NCL) is the isotropic compression line of normal compressed granular materials which is defined as the densest state of granular materials without shear dilatancy. It is essential to propose a reasonable equation for the NCL because it is usually used as the reference to describe the stress-strain relations of granular materials with different initial void ratios. In this paper, by introducing the above

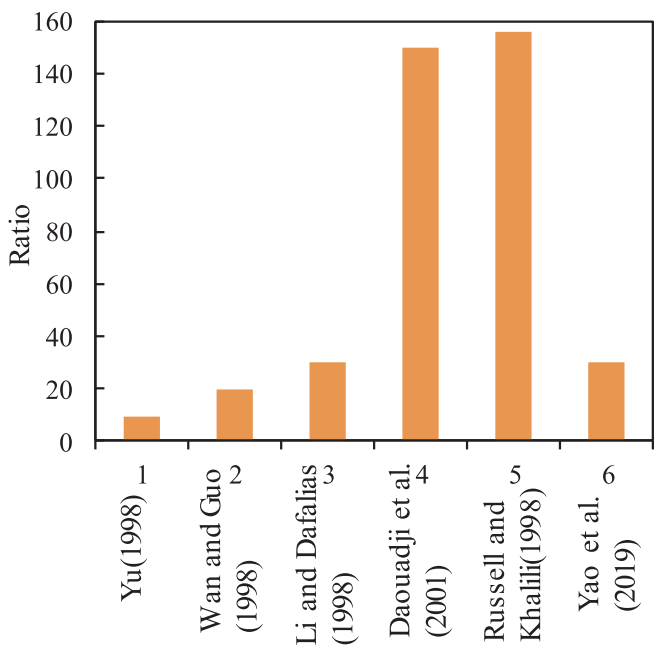

(a)

(b)

Fig. 1. Data collected of from some literatures: (a) maximum and minimum confining pressures; (b) ratios of the maximum to the minimum confining pressures. 


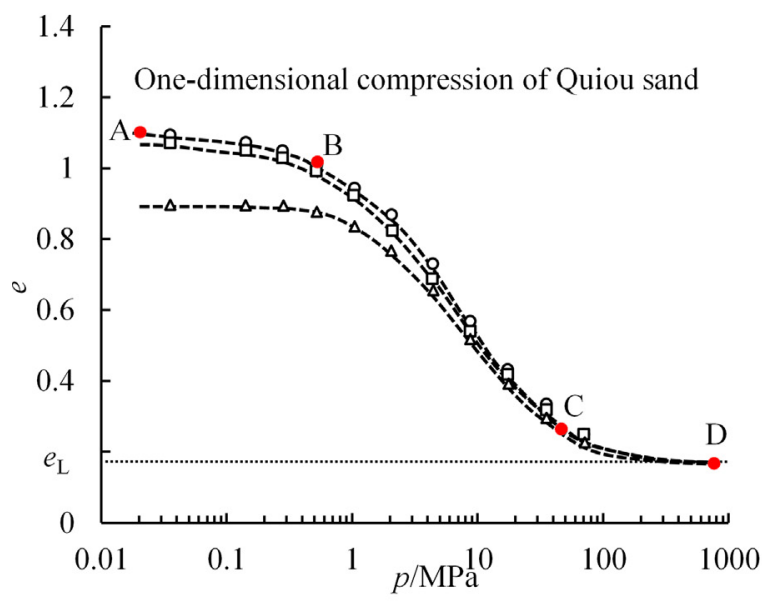

(a)

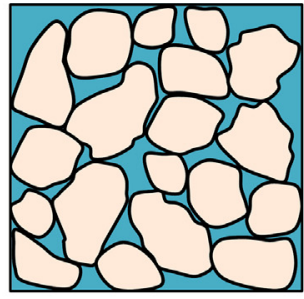

(A)

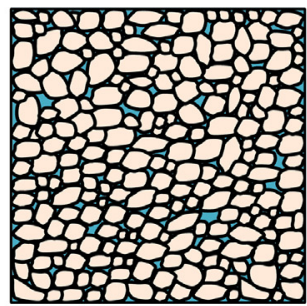

(D)

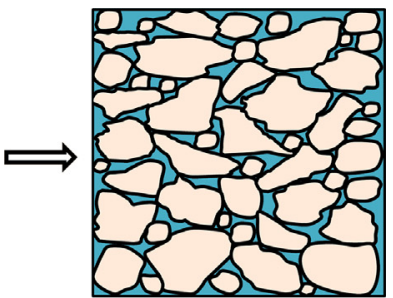

(B)

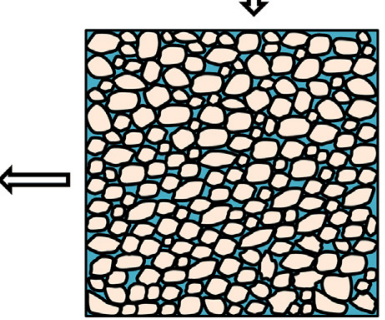

(C) (b)

Fig. 2. One-dimensional compression of Quiou sand: (a) void ratio-mean effective stress relations [12]; (b) crushing mechanism.

mentioned limit void ratio $e_{\mathrm{L}}$ and a compressive hardening parameter $p_{\mathrm{s}}$ [18] into double logarithmic coordinates, the NCL can be expressed as follows

$\ln \left(e-e_{\mathrm{L}}\right)=\ln \left(Z-e_{\mathrm{L}}\right)-\lambda \ln \left(\frac{p+p_{\mathrm{s}}}{1+p_{\mathrm{s}}}\right)$

where $Z$ is the void ratio when $p=1 \mathrm{kPa}$ on the NCL, $\lambda$ is the slope of the NCL in the space of $\ln \left(e-e_{\mathrm{L}}\right)$ versus $\ln \left(p+p_{\mathrm{s}}\right)$ When $p \rightarrow \infty$, $\ln \left(p+p_{\mathrm{s}}\right)$ is approximately equal to $\ln p$ and $\lambda$ is the slope of the asymptotic line in the space of $\ln \left(e-e_{\mathrm{L}}\right)$ versus $\ln p$, as shown in Fig. 3. $e_{\mathrm{L}}$ is the limit void ratio when the volume of the sample is no longer changing (see Point $\mathrm{D}$ in Fig. 2). $p_{\mathrm{s}}$ is the compressive hardening parameter. If $\left(N-e_{\mathrm{L}}\right)$ is the initial point at the asymptotic line with $p=1 \mathrm{kPa}$ (see Fig. 3), the compressive hardening parameter $p_{\mathrm{s}}$ can be derived as follows

$p_{\mathrm{s}}=\left(\frac{N-e_{\mathrm{L}}}{Z-e_{\mathrm{L}}}\right)^{\frac{1}{\lambda}}-1$

Similarly, the unloading line is expressed as follows

$\ln \left(e-e_{\mathrm{L}}\right)=\ln \left(e_{0}-e_{\mathrm{L}}\right)-\kappa \ln \left(\frac{p+p_{\mathrm{s}}}{p_{0}+p_{\mathrm{s}}}\right)$

where $\kappa$ is the slope of the unloading line in the space of $\ln \left(e-e_{\mathrm{L}}\right)$ versus $\ln \left(p+p_{\mathrm{s}}\right), e_{0}$ and $p_{0}$ are the initial void ratio and initial mean stress, respectively. We can derive the increments of total and elastic void ratios of normally compressed granular materials from Eqs. (1) and (3), respectively.

$\mathrm{d} e=-\lambda \frac{\left(e-e_{\mathrm{L}}\right) \mathrm{d} p}{p+p_{\mathrm{s}}}$

$\mathrm{d} e^{\mathrm{e}}=-\kappa \frac{\left(e-e_{\mathrm{L}}\right) \mathrm{d} p}{p+p_{\mathrm{s}}}$

The increment of total void ratio can also be rewritten as follows $\mathrm{d} e=\mathrm{d} e^{\mathrm{e}}+\mathrm{d} e^{\mathrm{p}}$

Thus, the increment of plastic void ratio can be derived from Eqs. (4)-(6) as follows

$\mathrm{d} e^{\mathrm{p}}=-(\lambda-\kappa)\left(e-e_{\mathrm{L}}\right) \frac{\mathrm{d} p}{p+p_{\mathrm{s}}}$
Eqs. (5) and (7) are the stress-strain relationship of normally compressed granular materials under isotropic compression condition.

\subsection{Yield surface}

As suggested in the literature [27-29], a drop-shaped yield surface can be a suitable choice for granular materials. Recently, a new and simple drop-shaped yield surface was proposed [18,30] (see Fig. 4). It can be written as follows

$f=\frac{(1+\chi) q^{2}}{M^{2} p^{2}-\chi q^{2}}+1-\frac{p_{x}}{p}=0$

where $\chi$ is the critical state parameter, and its value is non-negative but less than 1; $M$ is the critical state stress ratio; $p_{x}$ is the intersection of the yield surface with the $p$-axis. Eq. (7) can be rewritten as follows

$\frac{\mathrm{d} p}{p+p_{\mathrm{s}}}=\frac{-\mathrm{d} e^{\mathrm{p}}}{(\lambda-\kappa)\left(e-e_{\mathrm{L}}\right)}$

Integrating Eq. (9) generates

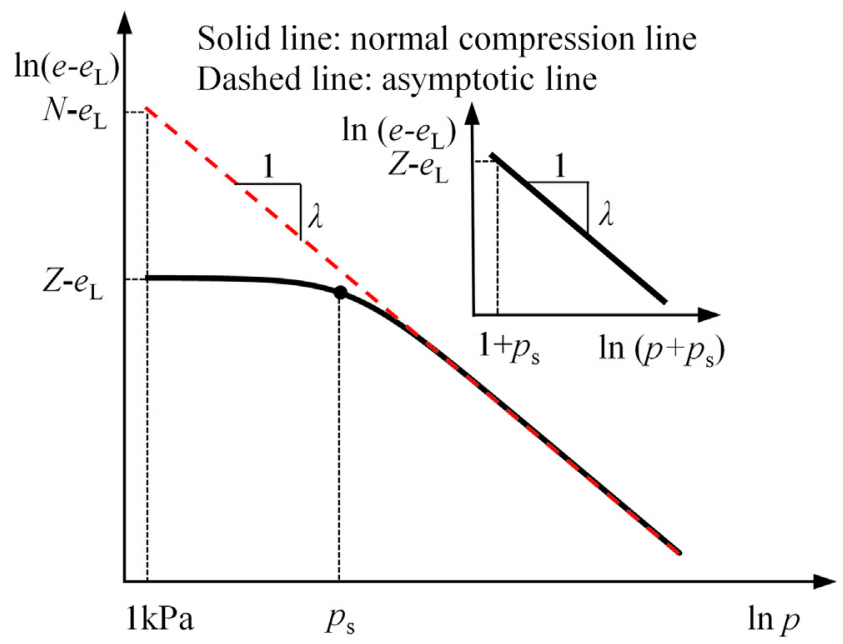

Fig. 3. NCL in $\ln \left(e-e_{\mathrm{L}}\right)-\ln p$ plane and $\ln \left(e-e_{\mathrm{L}}\right)-\ln \left(p+p_{\mathrm{s}}\right)$ space. 


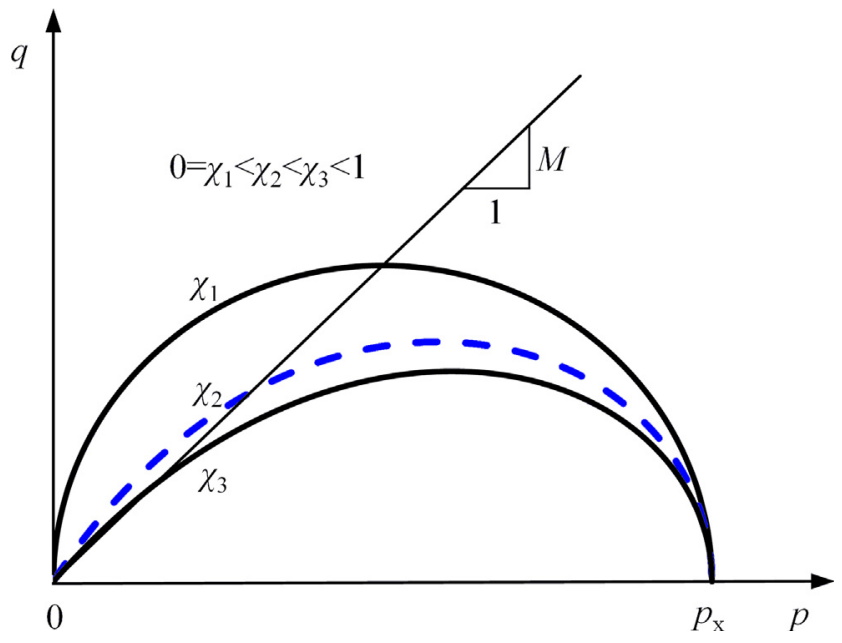

Fig. 4. Yield surfaces with different critical parameters.

$\int \frac{\mathrm{d} p}{p+p_{\mathrm{s}}}=-\int \frac{\mathrm{d} e^{\mathrm{p}}}{(\lambda-\kappa)\left(e-e_{\mathrm{L}}\right)}$

If the sample is loaded from $p_{x 0}$ to $p_{x}$, we can have

$\ln \frac{p_{x}+p_{\mathrm{s}}}{p_{x 0}+p_{\mathrm{s}}}=-\int \frac{\mathrm{d} e^{\mathrm{p}}}{(\lambda-\kappa)\left(e-e_{\mathrm{L}}\right)}$

Thus $p_{x}$ can be inversely solved from Eq. (11) as follows

$p_{x}=\left(p_{x 0}+p_{\mathrm{s}}\right) \exp \left(-\int \frac{\mathrm{d} e^{\mathrm{p}}}{(\lambda-\kappa)\left(e-e_{\mathrm{L}}\right)}\right)-p_{\mathrm{s}}$

Substituting Eq. (12) into Eq. (8), the yield function of normally compressed granular materials can written as follows

$f=\ln \left[\left(1+\frac{(1+\chi) q^{2}}{M^{2} p^{2}-\chi q^{2}}\right) p+p_{\mathrm{s}}\right]-\ln \left(p_{x 0}+p_{\mathrm{s}}\right)-\frac{1}{(\lambda-\kappa)} \int \frac{-\mathrm{d} e^{\mathrm{p}}}{\left(e-e_{\mathrm{L}}\right)}$ $=0$

Based on the UH model developed by Yao et al. [31], a hardening parameter $H$ is employed to replace the traditional hardening term (i.e., $\int \frac{- \text { dep }}{\left(e-e_{\mathrm{L}}\right)}$ in Eq. (13)) directly. Therefore, the yield function for granular materials can be written as follows

$f=\ln \left[\left(1+\frac{(1+\chi) q^{2}}{M^{2} p^{2}-\chi q^{2}}\right) p+p_{\mathrm{s}}\right]-\ln \left(p_{x 0}+p_{\mathrm{s}}\right)-\frac{1}{(\lambda-\kappa)} H=0$

where $H$ is the unified hardening parameter, which will be discussed in detail in the following section 'Hardening parameter'.

\subsection{Hardening parameter}

The unified hardening parameter [31,32] has been developed to describe the hardening/softening behavior with positive/negative dilation. The unified hardening parameter has been revised to consider some complicated conditions like rate-dependency and temperaturedependency [33,34]. In this paper, an updated unified hardening parameter $H$ is proposed as follows

$H=\int \frac{M_{\mathrm{f}}^{4}-\eta^{4}}{M_{\mathrm{c}}^{4}-\eta^{4}} \frac{-\mathrm{d} e^{\mathrm{p}}}{\left(e-e_{\mathrm{L}}\right)}$

where $M_{\mathrm{f}}$ is the potential failure stress ratio, and can be expressed as

$M_{\mathrm{f}}=6\left[\sqrt{\frac{12(3-M)}{M^{2}} \exp \left(-\frac{\xi}{\lambda-\kappa}\right)+1}+1\right]^{-1}$

where $M_{\mathrm{c}}$ is the characteristic state stress ratio, and can be expressed

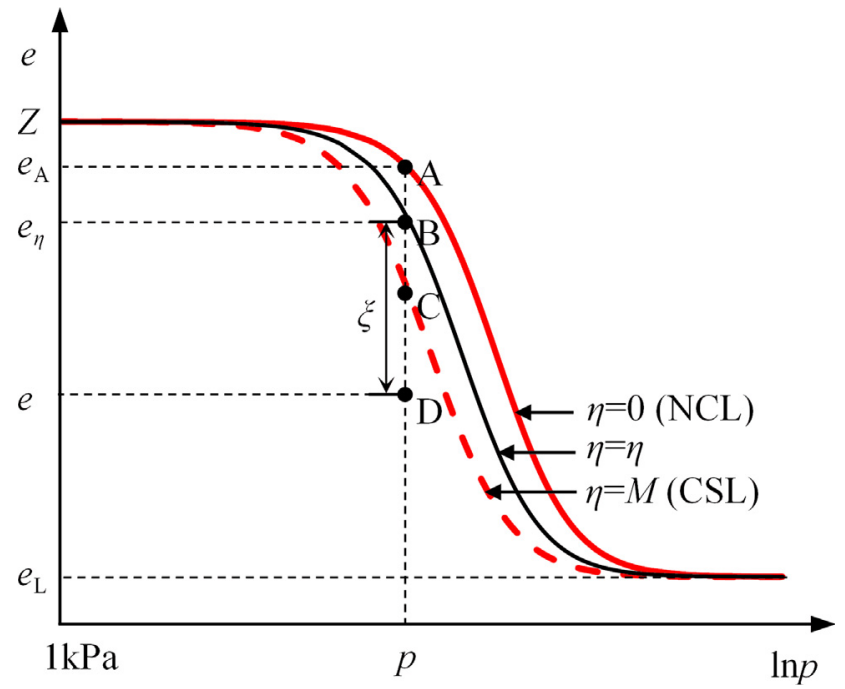

Fig. 5. NCL, ACL and CSL in $e-\ln p$ plane and state parameter $\xi$.

based on the literature of Li and Wang [35]

$M_{\mathrm{c}}=M \exp (-m \cdot \xi)$

where $m$ is a dilatancy parameter. $\xi$ is a state parameter related to shearing process. Reference to the state parameter $\left(\psi=e-e_{\mathrm{c}}\right)$ proposed by Been and Jefferies [36], $\xi$ is expressed as follows

$\xi=e_{\eta}-e$

where $e_{\eta}$ is the void ratio on an anisotropic compression line (ACL) of the normally compressed granular material at the current mean stress (see Point $\mathrm{B}$ in Fig. 5). Therefore, $e_{\eta}$ can be determined by the yield function of normally compressed granular materials (Eq. (13)). When the normally compressed granular materials is loaded along a constant $p$ path from Point A to Point $\mathrm{B}, e_{\eta}$ can be derived from Eq. (13).

$e_{\eta}=\left(e_{\mathrm{A}}-e_{\mathrm{L}}\right)\left(\frac{\frac{M^{2}+\eta^{2}}{M^{2}-\chi \eta^{2}} p+p_{\mathrm{s}}}{p+p_{\mathrm{s}}}\right)^{-(\lambda-\kappa)}+e_{\mathrm{L}}$

where $e_{\mathrm{A}}$ is the void ratio of Point $\mathrm{A}$ at the current stress. It can be calculated by Eq. (1).

$e_{\mathrm{A}}=\left(Z-e_{\mathrm{L}}\right)\left(\frac{p+p_{\mathrm{s}}}{1+p_{\mathrm{s}}}\right)^{-\lambda}+e_{\mathrm{L}}$

By combining Eqs. (18), (19) and (20), we can derive the equation of $\xi$ as follows

$\xi=\left(Z-e_{\mathrm{L}}\right)\left(\frac{p+p_{\mathrm{s}}}{1+p_{\mathrm{s}}}\right)^{-\lambda}\left(\frac{\frac{M^{2}+\eta^{2}}{M^{2}-\eta^{2}} p+p_{\mathrm{s}}}{p+p_{\mathrm{s}}}\right)^{-(\lambda-\kappa)}+e_{\mathrm{L}}-e$

\subsection{Plastic potential surface}

The plastic potential function in the paper is assumed as follows

$g=\ln \frac{p}{p_{y}}+\ln \left(1+\frac{q^{2}}{M_{\mathrm{c}}^{2} p^{2}}\right)=0$

where $p_{y}$ is the intersection of the current plastic potential surface with the $p$-axis. 


\subsection{Stress-strain relationship for triaxial compression states}

2.5.1. Strain increment

The elastic strain increment can be written as follows

$$
\left.\begin{array}{rl}
\mathrm{d} \varepsilon_{\mathrm{v}}^{\mathrm{e}} & =\frac{3(1-2 \nu)}{E} \mathrm{~d} p \\
\mathrm{~d} \varepsilon_{\mathrm{d}}^{\mathrm{e}} & =\frac{2(1+\nu)}{3 E} \mathrm{~d} q
\end{array}\right\}
$$

where $\nu$ is the Poisson's ratio, $\mathrm{d} \varepsilon_{\mathrm{v}}^{\mathrm{e}}$ is the elastic volumetric strain increment, $\mathrm{d} \varepsilon_{\mathrm{d}}^{\mathrm{e}}$ is the elastic deviatoric strain increment, $\mathrm{d} p$ is the mean stress increment, $\mathrm{d} q$ is the deviatoric stress increment, and $E$ is elastic modulus and can be expressed as

$E=\frac{3(1-2 v)\left(1+e_{0}\right)}{\left(e-e_{\mathrm{L}}\right) \cdot \mathcal{K}}\left(p+p_{\mathrm{s}}\right)$

The plastic strain increment is

$\mathrm{d} \varepsilon_{\mathrm{v}}^{\mathrm{p}}=\Lambda \frac{\partial g}{\partial p}$

where $\Lambda$ is the plastic factor and can be expressed as

$\Lambda=c_{p}\left(e-e_{\mathrm{L}}\right) \frac{M_{\mathrm{c}}^{4}-\eta^{4}}{M_{\mathrm{f}}^{4}-\eta^{4}} \frac{\frac{\partial f}{\partial p} \mathrm{~d} p+\frac{\partial f}{\partial q} \mathrm{~d} q}{\frac{\partial g}{\partial p}}$

where

$c_{\mathrm{p}}=(\lambda-\kappa) /\left(1+e_{0}\right)$

\subsubsection{Stress-strain relationship in $p$ - $q$ plane}

The stress-strain relationship for triaxial compression states can be written as follows

$\left\{\begin{array}{l}\mathrm{d} p \\ \mathrm{~d} q\end{array}\right\}=\left[\begin{array}{cc}K \cdot A_{1} & 3 K G \cdot A_{2} \\ 3 K G \cdot A_{3} & 3 G \cdot A_{4}\end{array}\right]\left\{\begin{array}{l}\mathrm{d} \varepsilon_{\mathrm{v}} \\ \mathrm{d} \varepsilon_{\mathrm{d}}\end{array}\right\}$

where $\mathrm{d} \varepsilon_{\mathrm{v}}$ is the total volumetric strain increment, $\mathrm{d} \varepsilon_{\mathrm{d}}$ is the total deviatoric strain increment, $K$ is the elastic bulk modulus, and $K=E /(3(1-2 v)) . \quad G$ is the elastic shear modulus, and $G=E /(2(1+\nu)) . A_{1}, A_{2}, A_{3}$ and $A_{4}$ can be derived as follows

$$
\left.\begin{array}{l}
A_{1}=\frac{B_{1}+B_{2}}{B_{1}+B_{2}+K c_{\mathrm{p}}\left(e-e_{\mathrm{L}}\right)\left(M_{\mathrm{c}}^{4}-\eta^{4}\right) B_{3}} \\
A_{2}=\frac{-2 c_{\mathrm{p}}\left(e-e_{\mathrm{L}}\right) M^{2} \eta(1+\chi)\left(M_{\mathrm{c}}^{4}-\eta^{4}\right)}{B_{1}+B_{2}+K c_{\mathrm{p}}\left(e-e_{\mathrm{L}}\right)\left(M_{\mathrm{c}}^{4}-\eta^{4}\right) B_{3}} \\
A_{3}=\frac{-2 c_{\mathrm{p}} \eta\left(e-e_{\mathrm{L}}\right)\left(M_{\mathrm{c}}^{2}+\eta^{2}\right) B_{3}}{B_{1}+B_{2}+K c_{\mathrm{p}}\left(e-e_{\mathrm{L}}\right)\left(M_{\mathrm{c}}^{4}-\eta^{4}\right) B_{3}} \\
A_{4}=\frac{B_{1}+K c_{\mathrm{p}}\left(e-e_{\mathrm{L}}\right)\left(M_{\mathrm{c}}^{4}-\eta^{4}\right) B_{3}}{B_{1}+B_{2}+K c_{\mathrm{p}}\left(e-e_{\mathrm{L}}\right)\left(M_{\mathrm{c}}^{4}-\eta^{4}\right) B_{3}}
\end{array}\right\}
$$

where

$$
\left.\begin{array}{c}
B_{1}=p\left(M_{\mathrm{f}}^{4}-\eta^{4}\right)\left(M^{2}-\chi \eta^{2}\right)\left[M^{2}+\eta^{2}+\left(M^{2}-\chi \eta^{2}\right) p_{\mathrm{s}} / p\right] \\
B_{2}=12 G c_{\mathrm{p}}\left(e-e_{\mathrm{L}}\right) M^{2} \eta^{2}(1+\chi)\left(M_{c}^{2}+\eta^{2}\right) \\
B_{3}=M^{4}-(1+3 \chi) M^{2} \eta^{2}-\chi \eta^{4}
\end{array}\right\}
$$

\subsection{Stress-strain relationship in general space}

Based on the SMP failure criterion [37], the proposed model is then extended from the triaxial compression to the three-dimensional by the transformed stress (TS) method [22]. It is worth noting that the TS method has been widely used by some researches [38,39] According to the Hooke's law, the stress increment tensor $\mathrm{d} \sigma_{i j}$ can be expressed as follows

$\mathrm{d} \sigma_{i j}=\mathrm{D}_{i j k l}^{\mathrm{e}} \mathrm{d} \varepsilon_{k l}^{\mathrm{e}}=\mathrm{D}_{i j k l}^{\mathrm{e}}\left(\mathrm{d} \varepsilon_{k l}-\mathrm{d} \varepsilon_{k l}^{\mathrm{p}}\right)$

where $\mathrm{d} \varepsilon_{k l}^{\mathrm{e}}$ is the elastic strain increment tensor, $\mathrm{d} \varepsilon_{k l}^{\mathrm{p}}$ is the plastic strain increment tensor, $\mathrm{d} \varepsilon_{k l}$ is the total strain increment tensor, and $\mathrm{D}_{i j k l}^{\mathrm{e}}$ is the elastic constitutive tensor. $\mathrm{D}_{i j k l}^{\mathrm{e}}$ can be expressed as

$\mathrm{D}_{i j k l}^{\mathrm{e}}=\left(K-\frac{2}{3} G\right) \delta_{i j} \delta_{k l}+G\left(\delta_{i k} \delta_{j l}+\delta_{i l} \delta_{j k}\right)$

In the TS space, the yield function can be written as

$\widetilde{f}=\ln \left[\left(1+\frac{(1+\chi) \widetilde{q}^{2}}{M^{2} \widetilde{p}^{2}-\chi \widetilde{q}^{2}}\right) \widetilde{p}+\widetilde{p}_{\mathrm{s}}\right]-\ln \left(\widetilde{p}_{x 0}+\widetilde{p}_{\mathrm{s}}\right)-\frac{1}{\lambda-\kappa} \widetilde{H}=0$

where

$\widetilde{H}=\int \frac{\widetilde{M}_{\mathrm{f}}^{4}-\widetilde{\eta}^{4}}{\widetilde{M}_{\mathrm{c}}^{4}-\widetilde{\eta}^{4}} \frac{-\mathrm{d} e^{\mathrm{p}}}{\left(e-e_{\mathrm{L}}\right)}$

where $\widetilde{M}_{\mathrm{f}}$ and $\widetilde{M}_{\mathrm{c}}$ can be calculated by Eqs. (16) and (17). The plastic potential function is

$\widetilde{g}=\ln \widetilde{p}+\ln \left(1+\frac{\widetilde{q}^{2}}{M_{\mathrm{c}}^{2} \widetilde{p}^{2}}\right)=0$

The plastic strain increment can be calculated by

$\mathrm{d} \varepsilon_{i j}^{\mathrm{p}}=\widetilde{\Lambda} \frac{\partial \widetilde{g}}{\partial \widetilde{\sigma}_{i j}}$

where $\widetilde{\Lambda}$ is the plastic factor in the TS space, and can be obtained by substituting Eqs. (33) and (36) into Eq. (31)

$\widetilde{\Lambda}=\frac{\frac{\partial \widetilde{f}}{\partial \sigma_{i j}} \mathrm{D}_{i j k l}^{\mathrm{e}} \mathrm{d} \varepsilon_{k l}}{\frac{\partial \widetilde{f}}{\partial \sigma_{i j}} \mathrm{D}_{i j k l}^{\mathrm{e}} \frac{\partial \widetilde{g}}{\partial \widetilde{\sigma} k l}-\frac{\partial \widetilde{f}}{\partial \widetilde{H}} \frac{\partial \widetilde{H}}{\partial e^{\mathrm{p}}} \frac{\partial e^{\mathrm{p}}}{\partial \varepsilon_{v}^{\mathrm{p}} \mathrm{p}} \frac{\partial \widetilde{g}}{\partial \widetilde{\sigma} m m}}$

Substituting Eqs. (37) and (36) into Eq. (31) gives

$\mathrm{d} \sigma_{i j}=\left[\mathrm{D}_{i j k l}^{\mathrm{e}}-\frac{\mathrm{D}_{i j m n}^{\mathrm{e}} \frac{\partial \widetilde{g}}{\partial \widetilde{\sigma}_{m n}} \frac{\partial \widetilde{f}}{\partial \sigma_{s t}} \mathrm{D}_{s t k l}^{\mathrm{e}}}{\frac{\partial \widetilde{f}}{\partial \sigma_{i j}} \mathrm{D}_{i j k l}^{\mathrm{e}} \frac{\partial \widetilde{g}}{\partial \widetilde{\sigma}_{k l}}-\frac{\partial \widetilde{f}}{\partial \widetilde{H}} \frac{\partial \widetilde{H}}{\partial e^{\mathrm{p}}} \frac{\partial e^{\mathrm{p}}}{\partial \varepsilon_{v}} \frac{\partial \widetilde{g}}{\partial \widetilde{\sigma}_{m m}}}\right] \mathrm{d} \varepsilon_{k l}$

Alternatively, the constitutive relation of the new model in the general stress space can be rewritten as follows

$\mathrm{d} \sigma_{i j}=\mathrm{D}_{i j k l}^{\mathrm{ep}} \mathrm{d} \varepsilon_{k l}$

where $\mathrm{D}_{i j k l}^{\mathrm{ep}}$ is the elasoplastic constitutive tensor. Therefore, we have

$\mathrm{D}_{i j k l}^{\mathrm{ep}}=\mathrm{D}_{i j k l}^{\mathrm{e}}-\frac{\mathrm{D}_{i j m n}^{\mathrm{e}} \frac{\partial \widetilde{g}}{\partial \widetilde{\sigma}_{m n}} \frac{\partial \widetilde{f}}{\partial \sigma_{s t}} \mathrm{D}_{s t k l}^{\mathrm{e}}}{\frac{\partial \widetilde{f}}{\partial \sigma_{i j}} \mathrm{D}_{i j k l}^{\mathrm{e}} \frac{\partial \widetilde{g}}{\partial \widetilde{\sigma} k l}-\frac{\partial \widetilde{f}}{\partial \widetilde{H}} \frac{\partial \widetilde{H}}{\partial e^{\mathrm{p}}} \frac{\partial e^{\mathrm{p}}}{\partial \varepsilon_{\varepsilon}^{\mathrm{p}}} \frac{\partial \widetilde{g}}{\partial \widetilde{\sigma}_{m m}}}$

where

$$
\left.\begin{array}{c}
\frac{\partial \widetilde{g}}{\partial \widetilde{\sigma_{i j}}}=\frac{1}{\widetilde{p}}\left[\frac{M_{\mathrm{c}}^{2}-\widetilde{\eta}^{2}}{M_{\mathrm{c}}^{2}+\widetilde{\eta}^{2}} \frac{\delta_{i j}}{3}+\frac{3\left(\widetilde{\sigma}_{i j}-\widetilde{p} \delta_{i j}\right)}{\widetilde{p}\left(M_{\mathrm{c}}^{2}+\widetilde{\eta}^{2}\right)}\right] \\
\frac{\partial \widetilde{f}}{\partial \widetilde{H}} \frac{\partial \widetilde{H}}{\partial e^{\mathrm{p}}} \frac{\partial e^{\mathrm{p}}}{\partial \varepsilon_{v}^{\mathrm{p}}}=-\frac{1}{c_{\mathrm{p}}} \frac{\widetilde{M}_{\mathrm{f}}^{4}-\widetilde{\eta}^{4}}{M_{\mathrm{c}}^{4}-\widetilde{\eta}^{4}} \frac{1}{e-e_{\mathrm{L}}} \\
\frac{\partial \widetilde{f}}{\partial \sigma_{i j}}=\frac{\partial \widetilde{f}}{\partial \widetilde{p}} \frac{\partial \widetilde{p}}{\partial \sigma_{i j}}+\frac{\partial \widetilde{f}}{\partial \widetilde{q}} \frac{\partial \widetilde{q}}{\partial \sigma_{i j}}
\end{array}\right\}
$$

where

$$
\begin{gathered}
\frac{\partial \widetilde{f}}{\partial \widetilde{p}}=\frac{M^{4}-(1+3 \chi) M^{2} \widetilde{\eta}^{2}-\chi \widetilde{\eta}^{4}}{\widetilde{p}\left(M^{2}-\chi \widetilde{\eta}^{2}\right)\left[M^{2}+\widetilde{\eta}^{2}+\left(M^{2}-\chi \widetilde{\eta}^{2}\right) p_{\mathrm{s}} / \widetilde{p}\right]} \\
\frac{\partial \widetilde{f}}{\partial \widetilde{q}}=\frac{2 M^{2}(1+\chi) \widetilde{\eta}}{\widetilde{p}\left(M^{2}-\chi \widetilde{\eta}^{2}\right)\left[M^{2}+\widetilde{\eta}^{2}+\left(M^{2}-\chi \widetilde{\eta}^{2}\right) p_{\mathrm{s}} / \widetilde{p}\right]} \\
\frac{\partial \widetilde{p}}{\partial \sigma_{i j}}=\frac{\delta_{i j}}{3} \\
\frac{\partial \widetilde{q}}{\partial \sigma_{i j}}=\sum_{m=1}^{3} \frac{\partial q_{c}}{\partial I_{m}} \frac{\partial I_{m}}{\partial \sigma_{i j}}
\end{gathered}
$$

where $I_{m}(m=1,2,3)$ is the stress invariant. 


\subsection{Loading-unloading criterion}

In the model, loading causes the elastoplastic deformations and the stress-strain relationship can be expressed by Eq. (39). Unloading only causes the pure elastic deformation and the stress-strain relationship can be expressed by Eq. (31). Therefore, the loading-unloading criterion can be summarised as follows

$\frac{\partial \widetilde{f}}{\partial \sigma_{i j}} D_{i j k l}^{\mathrm{e}} \mathrm{d} \varepsilon_{k l}>0 \quad$ loading

$\frac{\partial \widetilde{f}}{\partial \sigma_{i j}} D_{i j k l}^{\mathrm{e}} \mathrm{d} \varepsilon_{k l}=0 \quad$ neutral

$\frac{\partial \tilde{f}}{\partial \sigma_{i j}} D_{i j k l}^{\mathrm{e}} \mathrm{d} \varepsilon_{k l}<0 \quad$ unloading

\section{Model parameters}

All the parameters in the proposed model can be determined by conventional triaxial experiments. Parameters $\lambda, \kappa, N, M$ and $\nu$ are five classical material parameters in the critical state soil mechanics, where $\lambda, \kappa$ and $N$ can be determined by the isotropic loading and unloading tests and $M$ can be calculated from the friction angle at failure under triaxial compression condition. Poisson ratio $v$ is usually assumed a constant. In addition, $e_{\mathrm{L}}$ can be estimated by isotropic compression test or the critical state line at high stresses.

\subsection{Parameter $Z$}

In the proposed model, parameter $Z$ defines the location of the NCL and further determines the location of the critical state line (CSL). Thus the parameter $Z$ can be derived reversely based on the NCL and CSL. When granular materials is loaded along a constant $p$ path from Point A to Point C, as shown in Fig. 5, the void ratio of the critical state (Point C) can be solved from Eq. (19) by using the condition that $\eta=M$.

$e_{\eta=M}=\left(e_{\mathrm{A}}-e_{\mathrm{L}}\right)\left(\frac{\frac{2}{1-\chi} p+p_{\mathrm{s}}}{p+p_{\mathrm{s}}}\right)^{-(\lambda-\kappa)}+e_{\mathrm{L}}$

Therefore, the vertical distance between Point A and Point C can be calculated correspondingly

$\Delta e_{p}=e_{\mathrm{A}}-e_{\eta=M}=\left(e_{\mathrm{A}}-e_{\mathrm{L}}\right)\left[1-\left(\frac{\frac{2}{1-\chi} p+p_{\mathrm{s}}}{p+p_{\mathrm{s}}}\right)^{-(\lambda-\kappa)}\right]$

From Eq. (45), $\Delta e_{p}=0$ can be obtained at $p=0$ when $p_{\mathrm{s}}>0$. In other words, the CSL always coincides with the NCL at $p=0$ regardless the value of $\chi$ (see Fig. 6). Therefore, parameters $Z$ can be derived from Eq. (1)

$Z=\left(e_{\mathrm{c} 0}-e_{\mathrm{L}}\right)\left(\frac{p_{\mathrm{s}}}{1+p_{\mathrm{s}}}\right)^{\lambda}+e_{\mathrm{L}}$

where $e_{\mathrm{c} 0}$ is the void ratio at $p=0$ on the CSL, as shown in Fig. 6 . Compared with $1 \mathrm{kPa}$, the value of $p_{\mathrm{s}}$ of granular materials is very large, which implies that $\frac{p_{\mathrm{s}}}{1+p_{\mathrm{s}}}$ in Eq. (46) is approximately equal to 1 . Thus $Z$ can be set to be $e_{\mathrm{c} 0}$.

\subsection{Parameter $\chi$}

As shown in Fig. 7, parameter $\chi$ is employed to adjust the vertical distance between the NCL and CSL in the proposed model. Parameter $\chi$ can be derived reversely from Eq. (45) as follows

$\chi=1-\frac{2 p}{\left(1-\frac{\Delta e_{p}}{e_{\mathrm{A}}-e_{\mathrm{L}}}\right)^{\frac{1}{\lambda-\kappa}}\left(p+p_{\mathrm{s}}\right)-p_{\mathrm{s}}}$
If $\Delta e_{p}$ corresponding to a known stress $p$ has been measured according to test results, $\chi$ can be obtained by substituting the $\Delta e_{p}$ and the known stress $p$ into Eq. (47). In practice, if there are more experimental data about the critical states, $\chi$ can also be obtained by best fitting the experimental data. For example, it can be seen from Fig. 7 that the calculated CSL is consistent with the experimental observations when $\chi=0.7$. Moreover, it can be seen from Fig. 7 that the vertical distance between the NCL and CSL is very small at low stress level, and then, the distance gradually increases with the stress increasing. When the stress increases to very high, the distance starts to decrease with the stress increasing.

\subsection{Parameter $m$}

Parameter $m$ affects the evolution of the characteristic state stress ratio $M_{\mathrm{c}}$. Fig. 8 presents a schematic diagram of the undrained effective stress path of dense sand and its projection in the $e-p$ plane. As shown in Fig. 8, $M_{\mathrm{c}}^{\xi_{\mathrm{c}}}$ and a corresponding $p^{\xi_{\mathrm{c}}}$ can be measured from the effective stress path. Combining with $p=p^{\xi_{\mathrm{c}}}$ and $\eta=M_{\mathrm{c}}^{\xi_{\mathrm{c}}}, e_{\eta}$ can be calculated from Eq. (19), and then, $\xi_{\mathrm{c}}$ corresponding to $M_{\mathrm{c}}^{\xi_{\mathrm{c}}}$ also can be solved from Eq. (21). Substituting $\mathrm{M}_{\mathrm{c}}^{\xi_{\mathrm{c}}}$ and $\xi_{\mathrm{c}}$ into Eq. (17) gives

$m=-\frac{1}{\xi_{\mathrm{c}}} \ln \left(\frac{M_{\mathrm{c}}^{\xi_{\mathrm{c}}}}{M}\right)$

\section{Model validation}

\subsection{Determination of parameters}

Cambria sand is adopted here as an example to analyze some behaviors of granular marterials. According to the test results (as shown in Fig. 9) obtained by Lade and Yamamuro [15], all parameters in the model can be determined and are listed in Table 2. It is worth noting that the failure strength points or critical state points under triaxial compression conditions and triaxial extension conditions are not on the same curve in the $e-\log p$ space (see the Blue points in Fig. 9). It means that the CSLs obtained from laboratory tests are not unique. However, some literatures [40-42] have reported that because of the limitations of the testing equipment, such as varied and mixed boundary conditions, necking, the formation of shear band, the critical state is likely not to be achieved in laboratory tests, especially under triaxial extension condition. To overcome these weaknesses, the discrete-element method (DEM) is used to investigate the uniqueness of the critical state [43-45], and it is concluded that a unique CSL in the $e-\log p$ space can

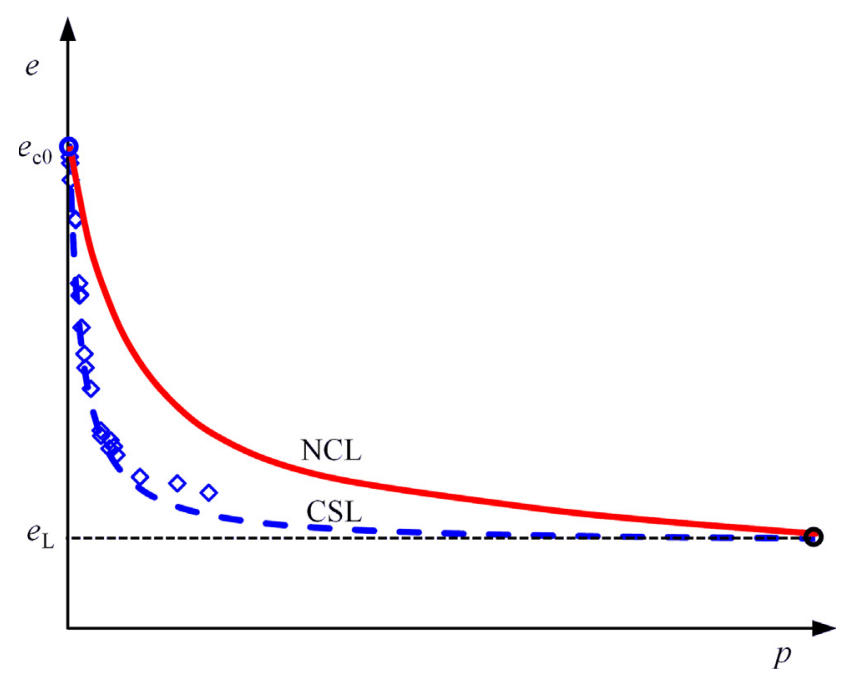

Fig. 6. NCL and CSL in the $e-p$ plane (data from Yamamuro and Lade [14]). 


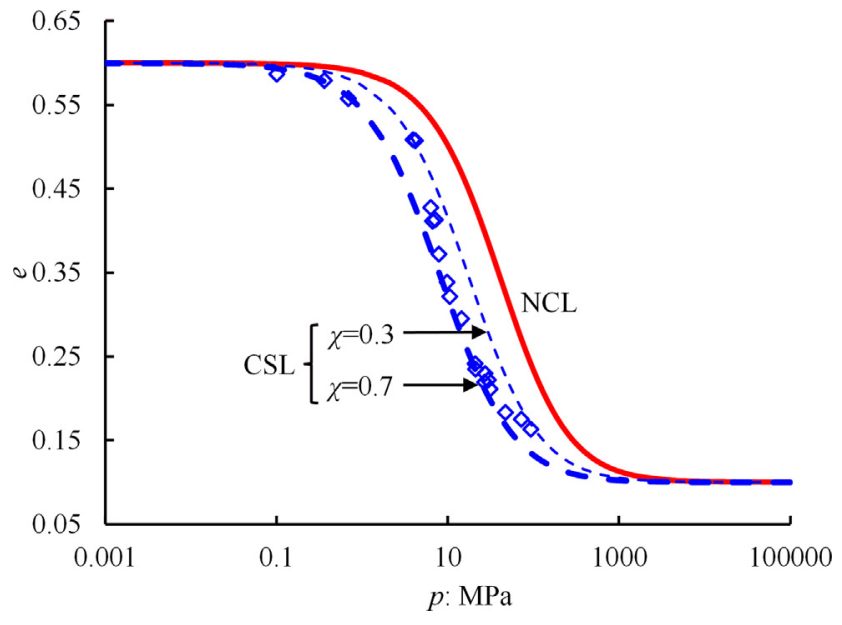

Fig. 7. Calibration of parameter $\chi$ (data from Yamamuro and Lade [14]).

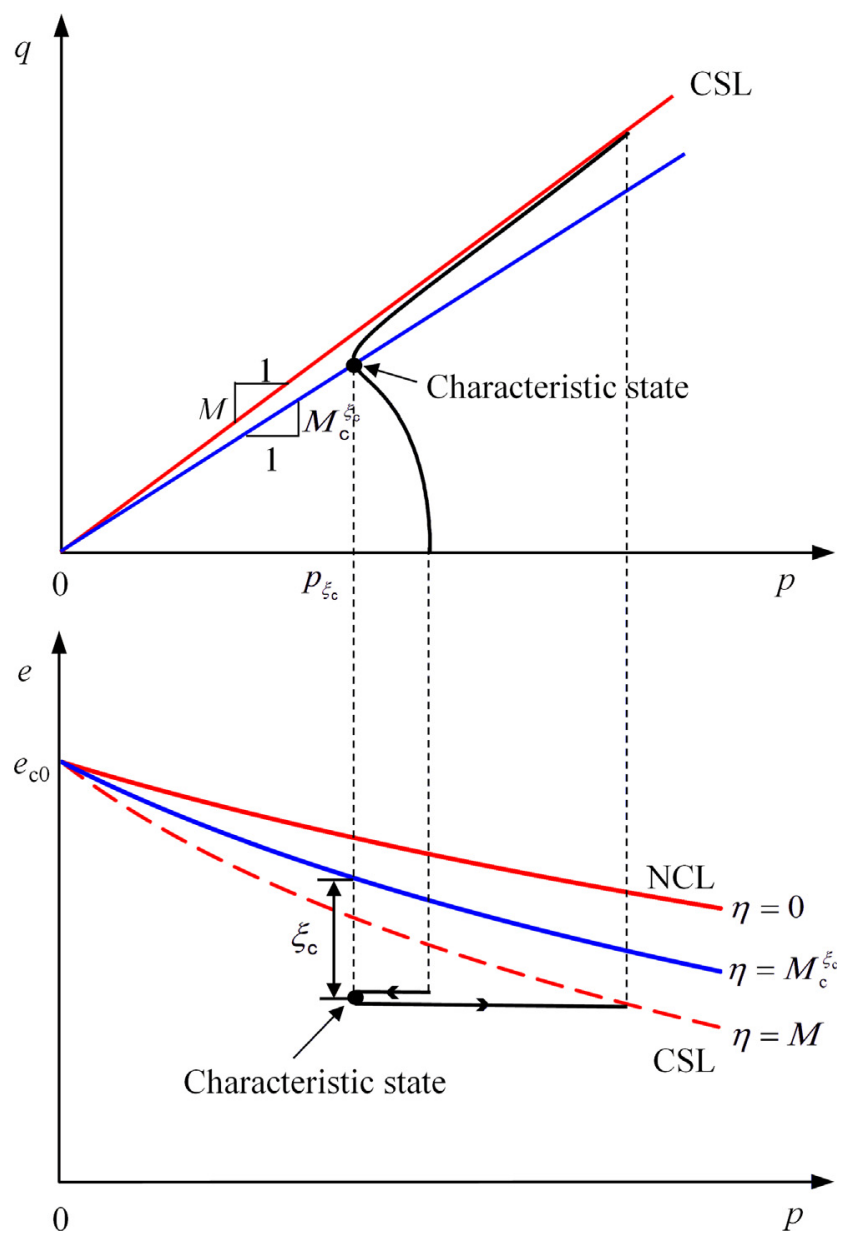

Fig. 8. Undrained effective stress path of dense sand and projection in the e-p plane.

be obtained irrespective of both initial fabric and the loading stress path. Therefore, the proposed model adopts a unique CSL, as seen the Blue solid line in Fig. 9.

Fig. 10 presents the predicted isotropic compression lines of Cambria sand with different initial void ratios. The slopes of all isotropic compression lines are very small at low stress level and compression lines gradually merge into each other as stress increases. When stress increases to a high stress, the volume changes gradually decreases. The volume change stops when stress increases to an ultra-high stress.

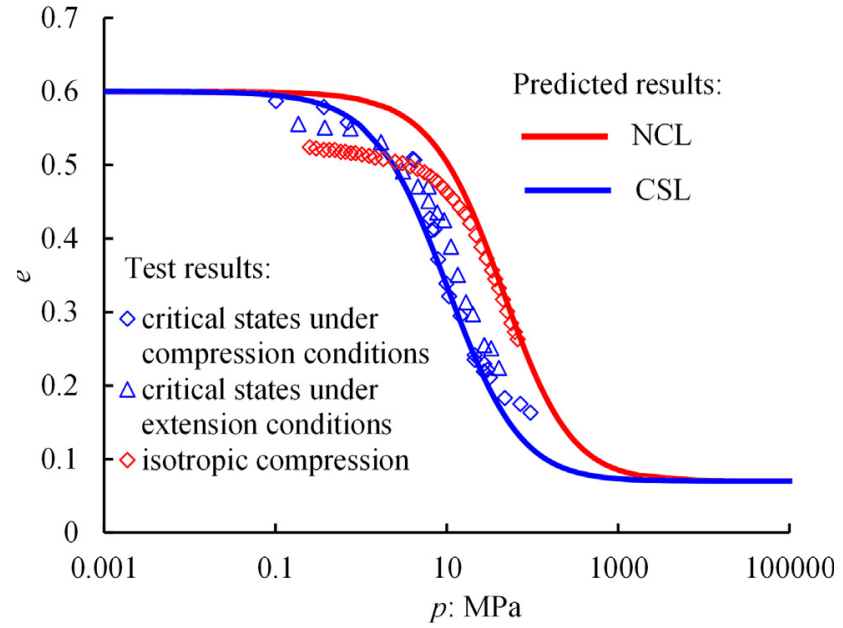

Fig. 9. Determination of parameters from isotropic compression line and critical state lines (data from Yamamuro and Lade [14]).

Table 2

Parameters calibrated for Cambria sand.

\begin{tabular}{llllllllll}
\hline Parameter & $M$ & $\lambda$ & $\kappa$ & $\nu$ & $N$ & $\chi$ & $m$ & $Z$ & $e_{\mathrm{L}}$ \\
\hline Value & 1.45 & 1.2 & 0.3 & 0.3 & 259,000 & 0.7 & 2.0 & 0.6 & 0.07 \\
\hline
\end{tabular}

\subsection{Model validation}

The experimental results of granular marterials over a wide range are relatively rare in the literature. Lade and Yamamuro [15] and Yamamuro and Lade [14] performed 12 undrained triaxial tests on Cambria sand at various confining pressures between 6.4 MPa and $68.9 \mathrm{MPa}$ and 26 drained triaxial tests at various confining pressures between $0.25 \mathrm{MPa}$ and $52 \mathrm{MPa}$. All of the test data will be used to verify the proposed constitutive model. The used parameters in the model are listed in Table 2. Note that for Cambria sand, this set of model parameters is constant for any densitties and stresses.

\subsubsection{Compression test}

The predictions of the new model and test results of Cambria sand under isotropic and one-dimensional compression conditions are displayed in Fig. 11. It can be seen that the predictions are consistent with

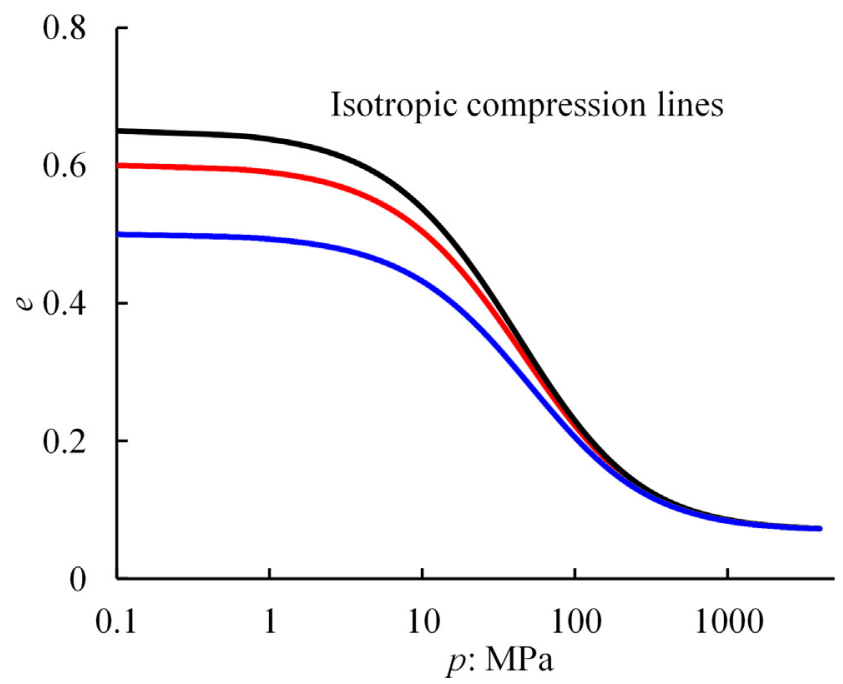

Fig. 10. Model simulations of isotropic compression of Cambria sand with different initial void ratios. 


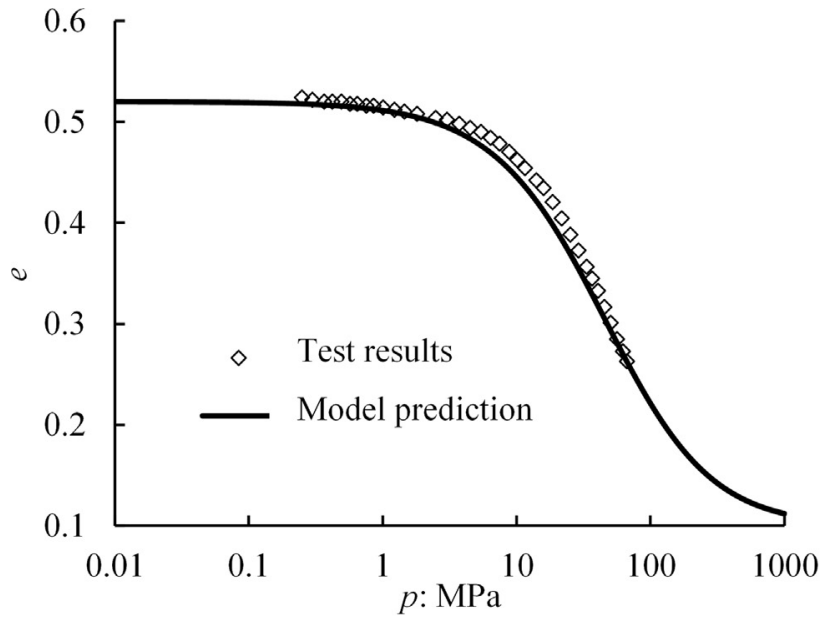

(a)

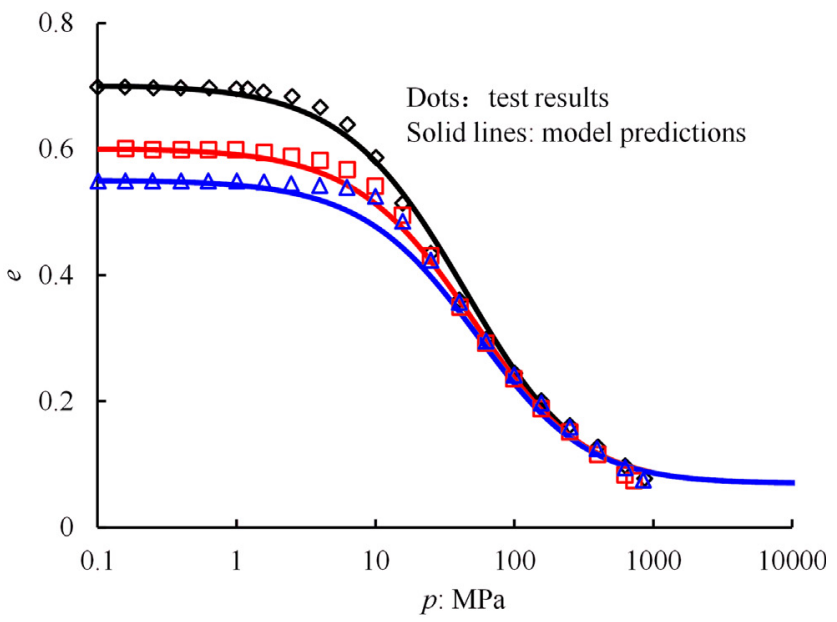

(b)

Fig. 11. Model predictions and test results: (a) isotropic compression (data from Yamamuro and Lade [14]); (b) one-dimensional compression (data from Yamamuro et al. [13]).

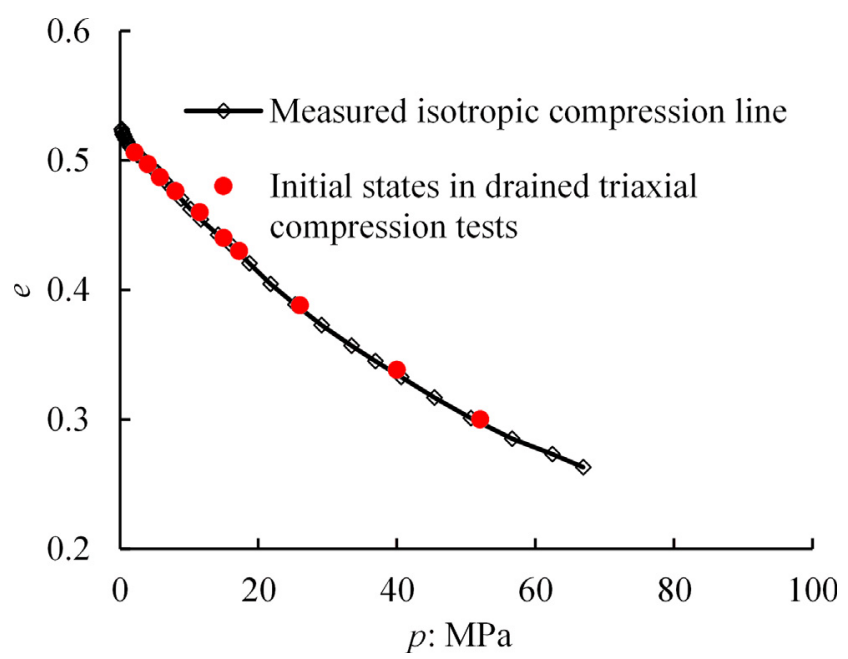

Fig. 12. Isotropic compression test results (data from Yamamuro and Lade [14]) and initial void ratios under drained triaxial compression shearing.

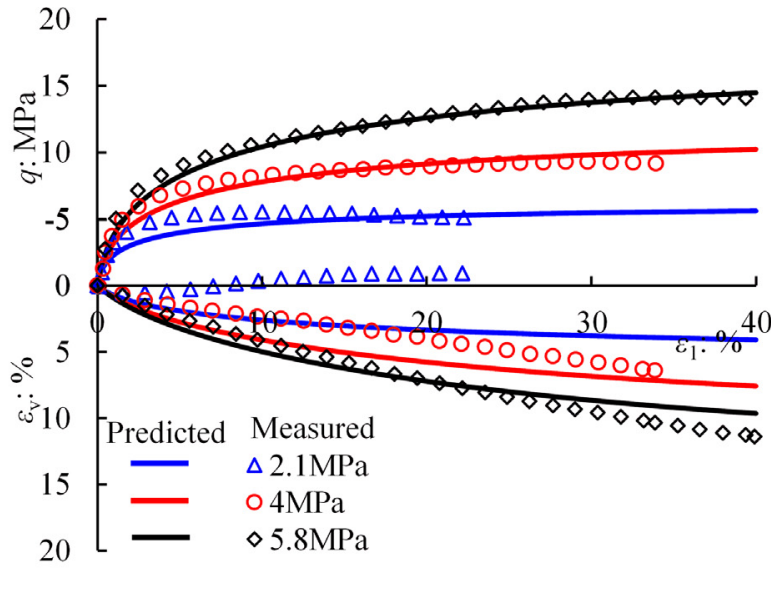

(a)

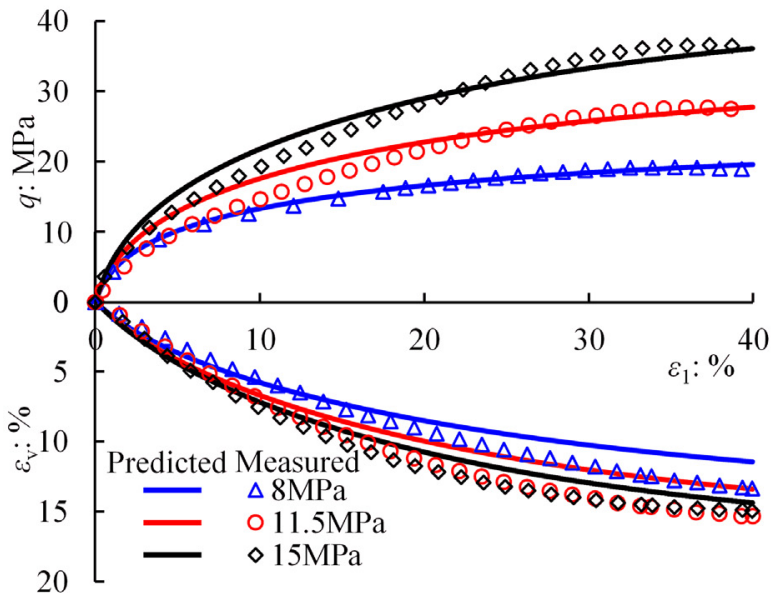

(b)

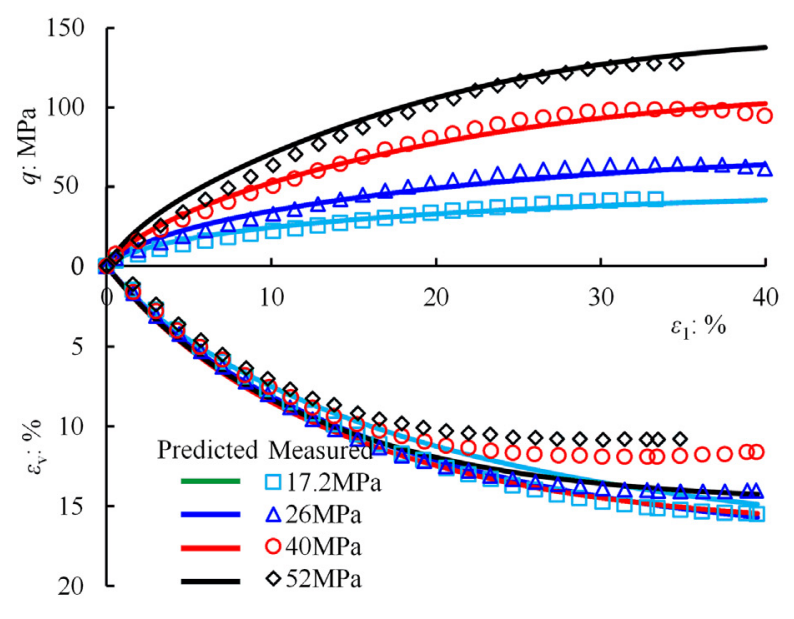

(c)

Fig. 13. Drained triaxial compression test results (data from Yamamuro and Lade [14]) and model predictions: (a)-(c) stress-strain relations and volumetric strains. 


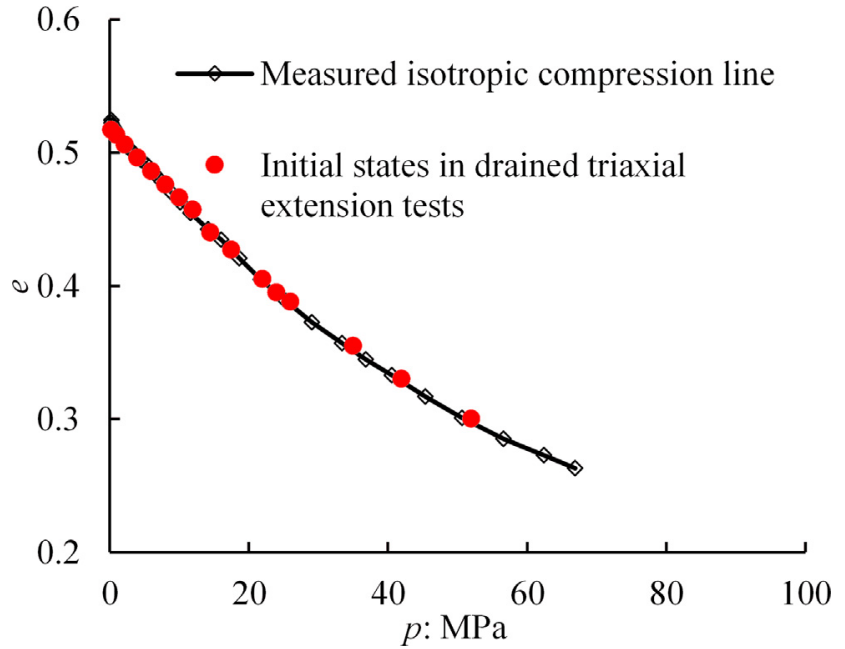

Fig. 14. Isotropic compression test results (data from Yamamuro and Lade [14]) and initial void ratios under drained triaxial extension shearing.

the test results.

\subsubsection{Drained shear test}

The drained shear tests contain the drained triaxial tests in both compression and extension.

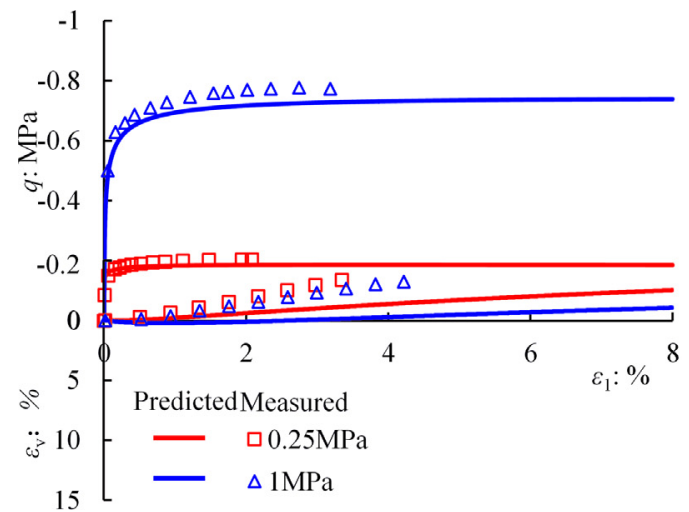

(a)

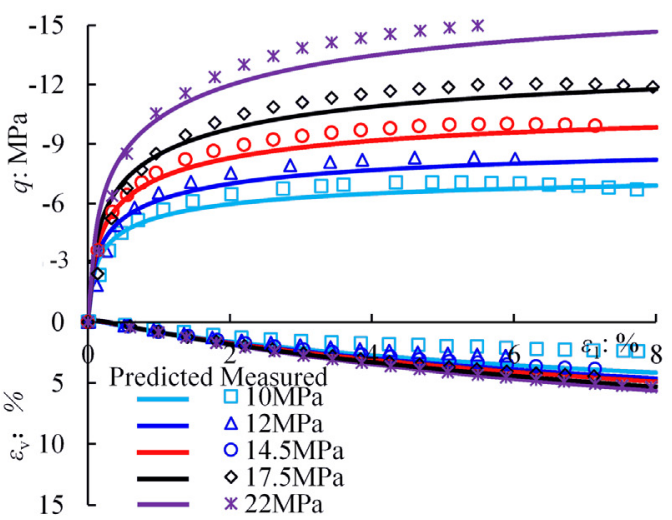

(c)

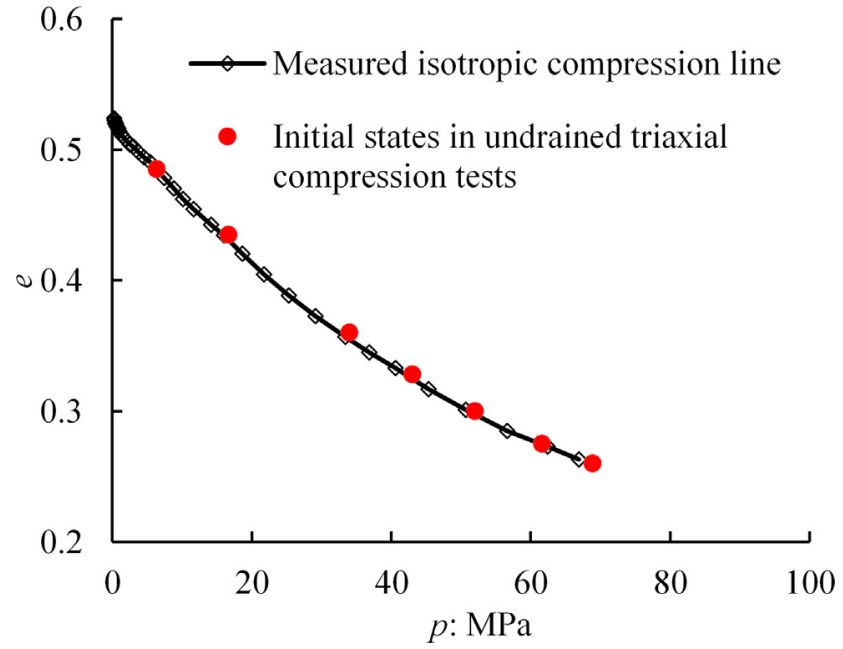

Fig. 16. Isotropic compression test results (data from Yamamuro and Lade [14]) and initial void ratios under undrained triaxial compression shearing.

(1) Drained triaxial compression tests

The initial void ratios of Cambria sand at different confining pressures can be determined according to the isotropic compression line, as shown in Fig. 12. The solid line with hollow dots stands for the measured results of isotropic compression and the solid dots present the

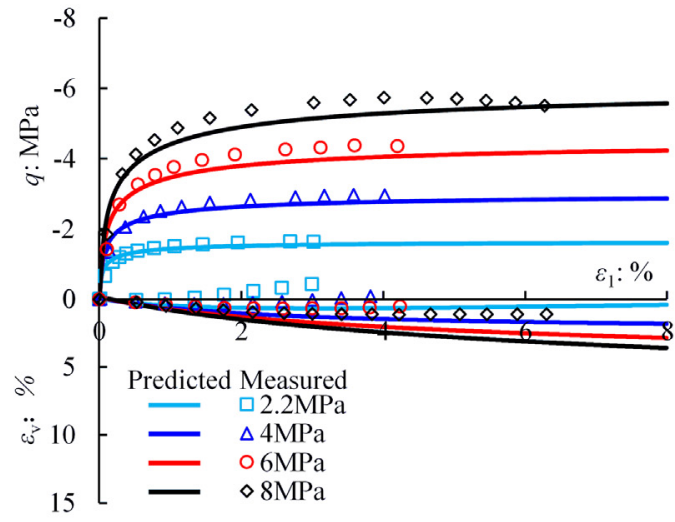

(b)

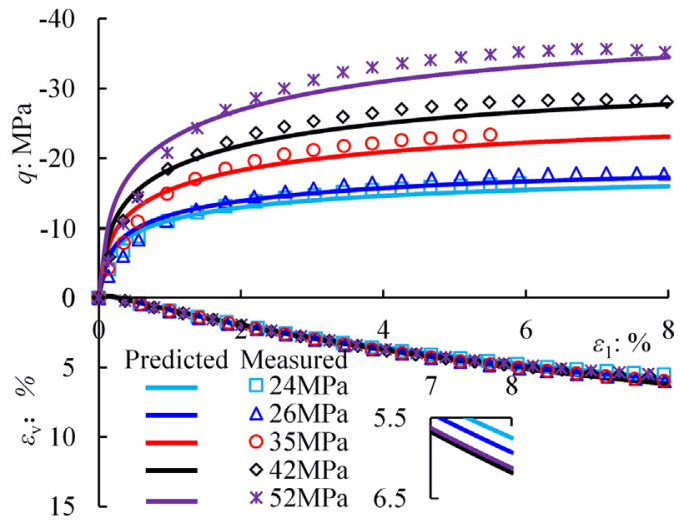

(d)

Fig. 15. Drained triaxial extension test results (data from Yamamuro and Lade [14]) and model predictions: (a)-(d) stress-strain relations and volumetric strains. 


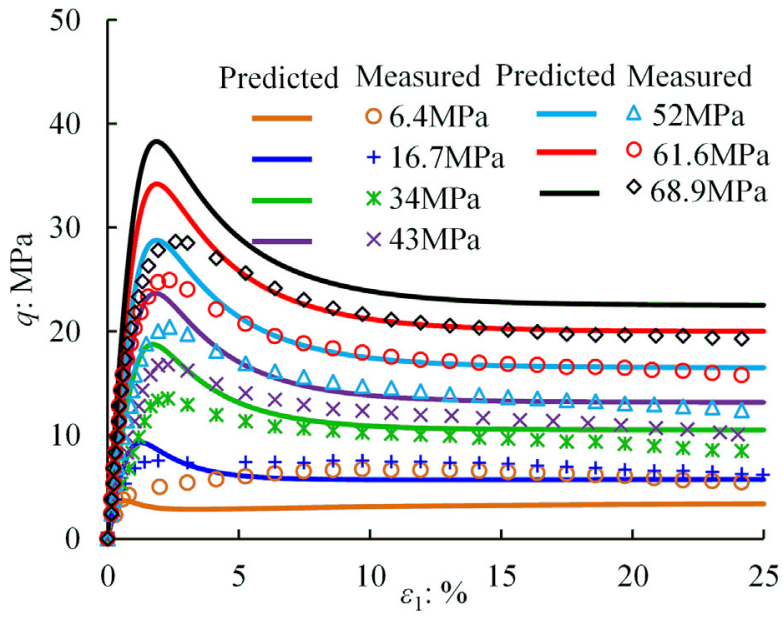

(a)

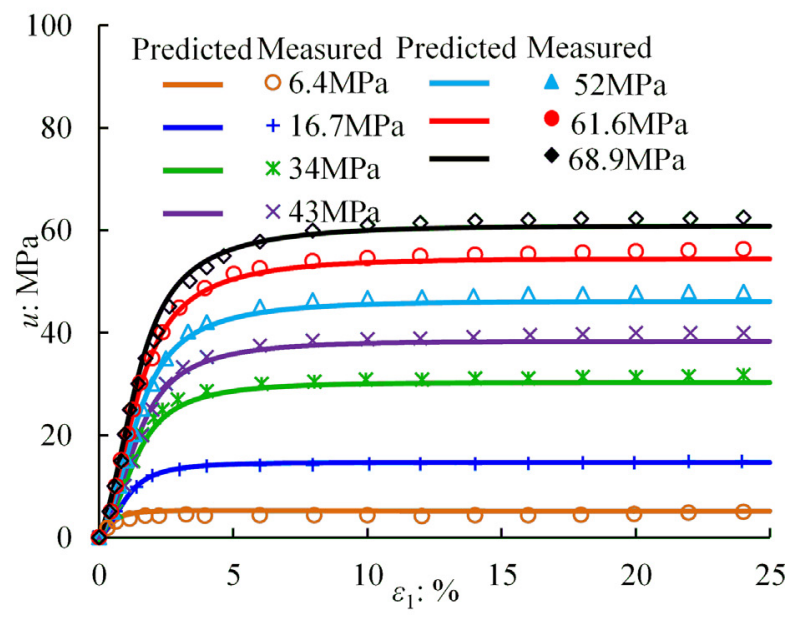

(b)

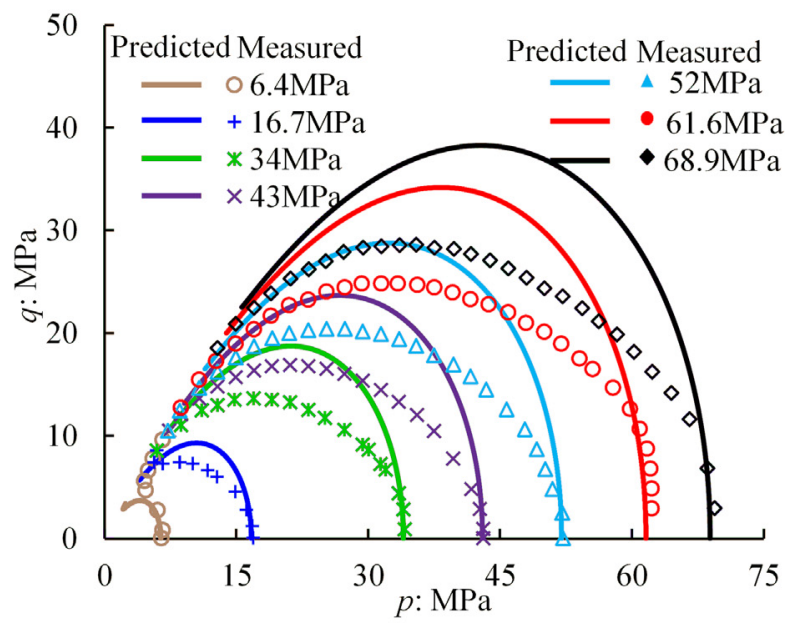

(b)

Fig. 17. Undrained triaxial compression test results (data from Lade and Yamamuro [15] and model predictions: (a) stress-strain relations; (b) pore pressures; (c) stress paths.

states after isotropic compression at different confining pressures. Fig. 13 shows the predicted and measured results of drained triaxial compression at different confining pressures. The predictions agree with the test results in general except there is some disparities for the

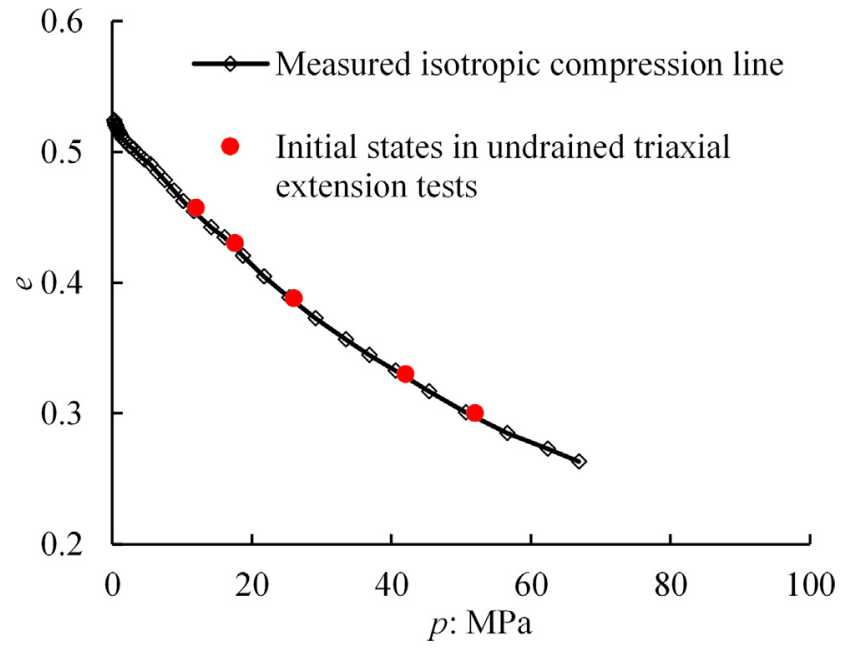

Fig. 18. Isotropic compression test results (data from Yamamuro and Lade [14]) and initial void ratios under undrained triaxial extension shearing.

volumetric strain at $p_{0}=2.1 \mathrm{MPa}$. In addition, it is worth noting that the shear strength gradually increases with increasing confining pressure, but the volumetric strain gradually increases and then decreases, and is the maximum at the confining pressure of $17.2 \mathrm{MPa}$, as shown in Fig. 13(c). It can be attributed that the slope of the CSL starts to decrease [14]. From Fig. 13, it has been verified that the new model can describe reasonably the above mentioned behaviors of granular materials.

\section{(2) Drained triaxial extension tests}

The states after isotropic compression but before shearing are shown by solid dots in Fig. 14. Fig. 15 shows that the drained extension test data of Cambria sand and the predictions at different confining pressures. It can be seen that the predictions of the stress-strain relations are consistent with the experimental observations in the whole testing stress range. In addition, it can also be observed that the tendency of voulmetric strain changing with the increasing of confining pressure is the same as that of drained triaxial compression tests, and the voulmetric strain is the maximum at the confining pressure of $35 \mathrm{MPa}$. The predicted voulmetric strains have the same tendency as the measured results, as shown in Fig. 15(c).

\subsubsection{Undrained shear test}

Undrained shear tests contain undrained triaxial tests in both compression and extension.

\section{(1) Undrained triaxial compression tests}

The initial states of Cambria sand in undrained shearing processes can be obtained from Fig. 16. The stress-strain relations, pore pressure relations and effective stress paths of Cambria sand at different confining pressures are shown in Fig. 17. In Fig. 17, the dots stand for the test results and the solid lines represent the predicted results by the proposed model. It is indicated that the proposed model can fit well the test data for the whole testing range from 6.4 MPa to 68.9 MPa, which illustrates that the proposed model is applicable to reflect the stressstrain behaviors of granular materials over a very lager stress range.

\section{(2) Undrained triaxial extension tests}

The initial states before undrained shearing are shown by solid dots in Fig. 18. The predictions and the results of undrained triaxial extension tests are represented in Fig. 19. Comparison with test results 


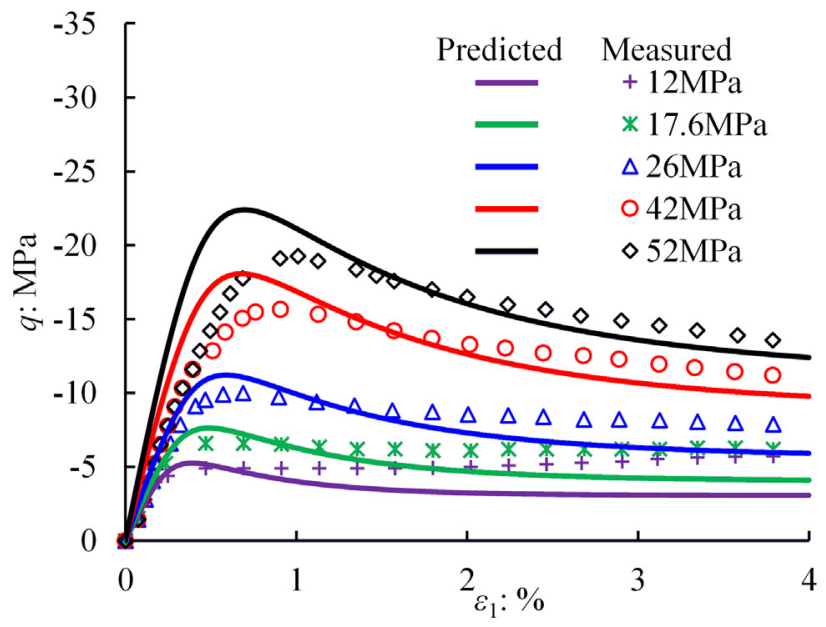

(a)

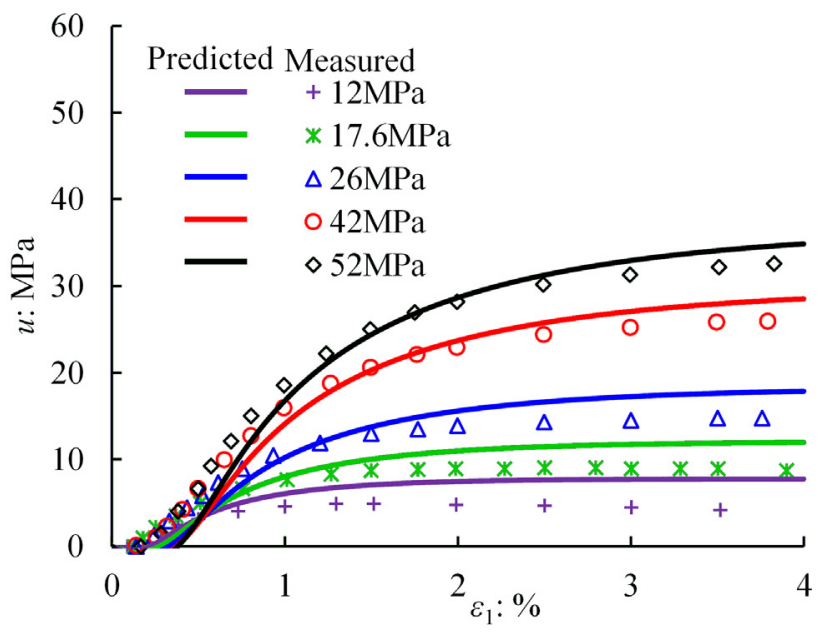

(b)

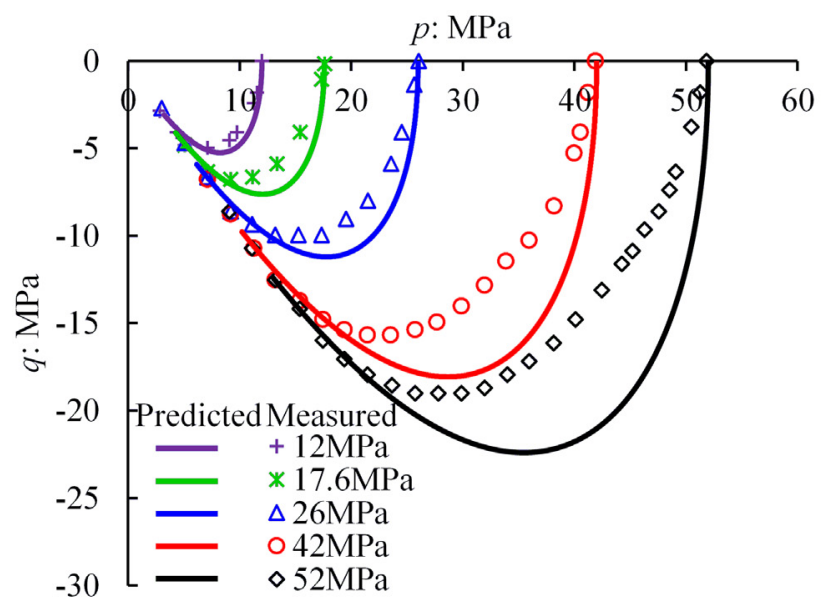

(c)

Fig. 19. Undrained triaxial extension test results (data from Lade and Yamamuro [15]) and model simulations: (a) stress-strain relations; (b) pore pressures; (c) stress paths.

indicates that the model is capable of predicting responses of Cambria sand subjected to undrained triaxial extension over a wide range of stresses (12-52 MPa).

\section{Conclusions}

A constitutive model is proposed in this paper to describe the mechanical behaviors of granular materials subjected to large stress range. It requests only 9 parameters, all of which have specific physical meaning and can be conveniently determined by laboratory tests.

By adopting a single set of material parameters, the model is able to describe the mechanical behaviors of granular materials subjected to different load paths. The S-shaped compression line, as observed in isotropic compression tests and one-dimensional compression tests, is reasonably described. The phenomena that the volumetric strains will not increase continually with growing initial confining pressures in drained triaxial compression/extension tests is simulated. The pore pressures in undrained triaxial compression/extension tests are simulated accurately.

According to the literature we already have, the model may be the first constitutive model to be able to predict the behaviors of granular materials subjected to high stress of $68.9 \mathrm{MPa}$. In addition, the model is verified by 42 sets of tests, and in these tests the ratio of maximum confining pressure to minimum confining pressure is 275.6. This implies that the model is applicable not only to high pressure, but also to extra-large pressure range.

\section{CRediT authorship contribution statement}

Lin Liu: Investigation, Methodology, Data curation, Writing - original draft. Yangping Yao: Conceptualization, Methodology, Supervision, Funding acquisition. Ting Luo: Validation, Funding acquisition. Annan Zhou: Writing - review \& editing.

\section{Declaration of Competing Interest}

The authors declare that they have no known competing financial interests or personal relationships that could have appeared to influence the work reported in this paper.

\section{Acknowledgements}

This work was supported by the National Program on Key Basic Research Project of China (973 Program, Grant No. 2014CB047001), the National Natural Science Foundation of China (Grant Nos. 51579005 and 11672015).

\section{References}

[1] Coop MR, Sorensen KK, Freitas TB, Georgoutsos G. Particle breakage during shearing of a carbonate sand. Géotechnique 2004;54(3):157-63.

[2] Jin YF, Wu ZX, Yin ZY, et al. Estimation of critical state-related formula in advanced constitutive modeling of granular material. Acta Geotech 2017;12(6):1329-51.

[3] Lee KL, Seed HB. Drained strength characteristics of sands. J Soil Mech Found Div 1967;93(6):117-41.

[4] Vesic AS, Clough GW. Behavior of granular materials under high stresses. J Soil Mech Found Div 1968;94(3):661-88.

[5] Yin ZY, Hicher PY, Dano C, Jin YF. Modeling mechanical behavior of very coarse granular materials. J Eng Mech, Am Soc Civ Eng 2017;143(1). Doi: 10.1061/(ASCE) EM.1943-7889.0001059.

[6] Yoshimine M, Ishihara K, Vargas W. Effects of principal stress direction and intermediate principal stress on undrained shear behavior of sand. Soils Found 1998;38(3):179-88.

[7] Yoshimine M, Ishihara K, Vargas W. Effects of principal stress direction and intermediate principal stress on undrained shear behavior of sand. J Jpn Geotech Soc 2008;38(3):179-88.

[8] Lu XB, Zhang XH, Wang PK, Liang QY. Advances of formation dynamics of natural gas hydrate (in Chinese). Sci Sin-Phys Mech Astron 2019;49:034605. https://doi. org/10.1360/SSPMA2018-00362.

[9] Pestana JM, Whittle AJ. Compression model for cohesionless soils. Géotechnique 1995;45(45):611-31.

[10] Roberts JE, de Souza JM. The compressibility of sand. Proc Am Soc Test Mat 1958;58:1269-77.

[11] Hendron A. The behavior of sand in one-dimensional compression $\mathrm{PhD}$ dissertation Urbana: Univ. of Illinois; 1963.

[12] Hagerty MM, Hite DR, Ullrich CR, Hagerty DJ. One-dimensional high-pressure 
compression of granular media. J Geotech Engng 1993;119(1):1-18.

[13] Yamamuro JA, Bopp PA, Lade PV. One-dimensional compression of sands at high pressures. J Geotech Engrg 1996;122(2):147-54.

[14] Yamamuro JA, Lade PV. Drained sand behavior in axisymmetric tests at high pressures. J Geotech Engrg 1996;122(2):120-9.

[15] Lade PV, Yamamuro JA. Undrained sand behavior in axisymmetric tests at high pressures. J Geotech Engng 1996;122(2):109-19.

[16] Yu HS. CASM: a unified state parameter model for clay and sand. Int J Numer Anal Meth Geomech 1998;22(8):621-53.

[17] Daouadji A, Hicher PY, Rahma A. An elastoplastic model for granular materials taking into account grain breakage. Europ J Mech 2001;20(1):113-37.

[18] Yao YP, Liu L, Luo T, Tian Y, Zhang JM. Unified hardening (UH) model for clays and sands. Comput Geotech 2019;110:326-43.

[19] Wan RG, Guo PJ. A simple constitutive model for granular soils: modified stressdilatancy approach. Comput Geotech 1998;22(2):109-33.

[20] Li XS, Dafalias YF. Dilatancy for cohesionless soils. Géotechnique 2000;50(4):449-60.

[21] Russell AR, Khalili N. A bounding surface plasticity model for sands exhibiting particle crushing. Can Geotech J 2004;41(6):1179-92.

[22] Yao YP, Wang ND. Transformed stress method for generalizing soil constitutive models. J Eng Mech 2014;140(3):614-29.

[23] Bolton MD, Nakata Y, Cheng YP. Micro and macro-mechanical behaviour of DEM crushable materials. Géotechnique 2008;58(58):471-80.

[24] Cheng YP. Discrete element simulation of crushable soil. Géotechnique 2003;53(7):633-42.

[25] Danda S, Lin Z, Jianfeng X, Jing S. DEM modeling of particle breakage in silica sands under one-dimensional compression. Acta Mech Solida Sin 2016;29(1):78-94.

[26] Mcdowell G, Bono JD. On the micro mechanics of one-dimensional normal compression. Géotechnique 2013;63(11):895-908.

[27] Yao YP, Sun DA, Luo T. A critical state model for sands dependent on stress and density. Int J Numer Anal Meth Geomech 2004;28(4):323-37.

[28] Yao YP, Sun DA, Matsuoka H. A unified constitutive model for both clay and sand with hardening parameter independent on stress path. Comput Geotech 2008;35(2):210-22.

[29] Yao YP, Wang ND. Constitutive model considering sand crushing. Soils Found
2008;48(4):603-8.

[30] Yao YP, Liu L, Luo T. UH model for sands. Chinese J Geotech Eng 2016;38(12):2147-53.

[31] Yao YP, Hou W, Zhou AN. UH model: three-dimensional unified hardening model for overconsolidated clays. Géotechnique 2009;59(5):451-69.

[32] Yao YP, Gao ZW, Zhao JD, Wan Z. Modified UH model: constitutive modeling of overconsolidated clays based on a parabolic hvorslev envelope. J Geotech Geoenviron Eng 2012;138(7):860-8.

[33] Yao YP, Kong LM, Zhou AN, Yin JH. Time-dependent unified hardening model: three-dimensional elastoviscoplastic constitutive model for clays. J Eng Mech 2015;141(6):4014162.

[34] Yao YP, Zhou AN. Non-isothermal unified hardening model: a thermo-elastoplastic model for clays. Géotechnique 2013;63(15):1328-45.

[35] Li XS, Wang Y. Linear representation of steady-state line for sand. J Geotech Geoenviron Eng 1998;124(12):1215-7.

[36] Been K, Jefferies MG. A state parameter for sands. Géotechnique 1985;35(2):99-112.

[37] Matsuoka H, Nakai T. Stress-deformation and strength characteristics of soil under three different principal stresses. Proc Jpn Soc Civ Ehbrs 1974;232:59-70.

[38] Lai YM, Liao MK, Hu K. A constitutive model of frozen saline sandy soil based on energy dissipation theory. Int J Plast 2016;78:84-113.

[39] Lu DC, Zhou X, Du XL, Wang GS. A 3D fractional elastoplastic constitutive model for concrete material. Int J Solids Struct 2019;165(6):160-75. https://doi.org/10. 1016/j.ijsolstr.2019.02.004.

[40] Imam SR, Morgenstern NR, Robertson PK, Chan DH. A critical-state constitutive model for liquefiable sand. Can Geotech J 2005;42(3):830-55.

[41] Yang ZX, Li XS, Yang J. Quantifying and modelling fabric anisotropy of granular soils. Geotechnique 2008;58(4):237-48.

[42] Yang ZX, Wu Y. Critical state for anisotropic granular materials: a discrete element perspective. Int J Geomech 2017;17(2):04016054.

[43] Sitharam TG, Vinod JS. Critical state behaviour of granular materials from isotropic and rebounded paths: DEM simulations. Granular Matter 2009;11(1):33-42.

[44] Yan WM, Zhang L. Fabric and the critical state of idealized granular assemblages subject to biaxial shear. Comput Geotech 2013;49:43-52.

[45] Zhao J, Guo N. Unique critical state characteristics in granular media considering fabric anisotropy. Geotechnique 2013;63(8):695-704. 